\title{
The Effect of Suspended Sediment Loads on the Growth, Oxygen Consumption and Mucus Production of Pāua (Haliotis iris)
}

\author{
A thesis submitted in \\ Fulfilment of the requirements for the Degree of \\ Master of Science \\ In the \\ School of Biological Sciences \\ Victoria University of Wellington \\ By \\ Taputukura Raea
}

December 2013 


\begin{abstract}
Land based-effects, including sedimentation are threatening estuarine and coastal systems globally. Ecological systems are faced with significant pressures from human activities including toxic pollution, eutrophication, habitat fragmentation and sedimentation. In recent years sediment inputs into marine systems have been greatly accelerated through land-based activities such as urban-land use, agriculture, coastal developments, large scale land clearances and farming. Effects of sedimentation on marine organisms include suffocation, reduced foraging efficiency and clogging of the gills of filter feeders.

In New Zealand, sedimentation is the most important land-based stressor on the coastal marine environment. The pāua (Haliotis iris), is an important macroalgal grazer and is one of New Zealand's top 10 seafood exports. However, little is known about the effects suspended sediments have on $H$. iris. The aim of this thesis is to experimentally test the effects of suspended sediment on the growth, oxygen consumption and mucus production for $H$. iris, using sediment concentrations that would naturally occur within Wellington Harbour, New Zealand.

Suspended sediment had no significant effect on $H$. iris growth or oxygen consumption. However, exposure to suspended sediments significantly reduced mucus production in $H$. iris. There were also trends in the data to suggest that respiration in smaller $H$. iris was reduced by suspended sediments.

Limited studies have explored the effect of suspended sediments on gastropods, even though sedimentation is one of the most significant land based stressors on the marine environment, not only in New Zealand, but also worldwide. This study has led to a better understanding of the potential implications suspended sediment may incur for not only $H$. iris, but also Haliotis species in general.
\end{abstract}




\section{Table of Contents}

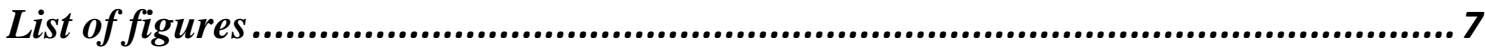

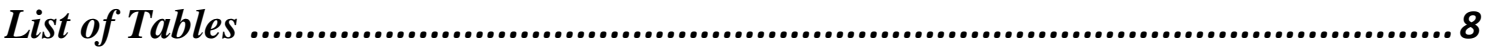

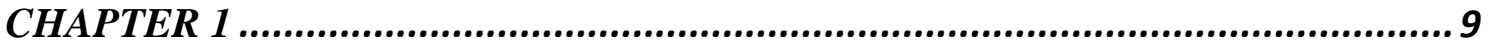

The effects of suspended sediment on the black foot abalone Haliotis iris ........................9

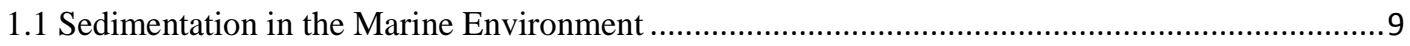

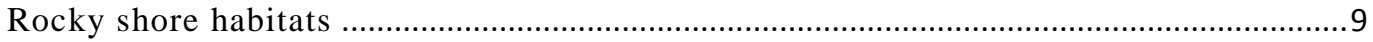

Effects of sediment on marine organisms ....................................................................

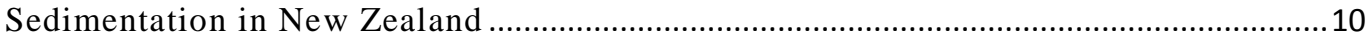

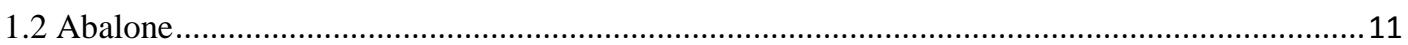

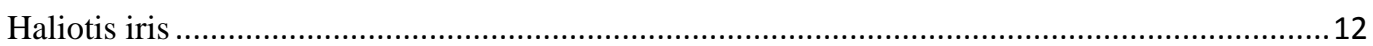

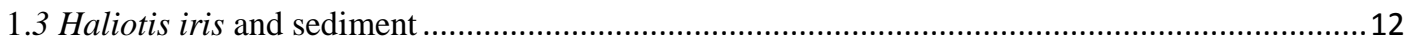

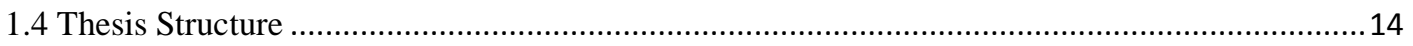

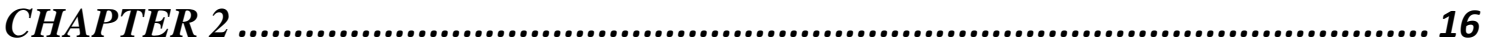

The Effect of Suspended Sediment on the Growth of the Black foot Abalone, Haliotis

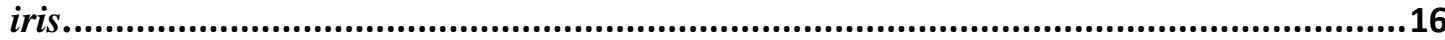

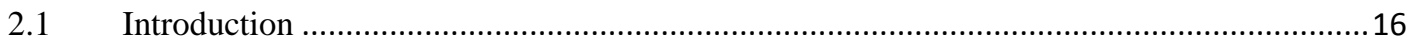

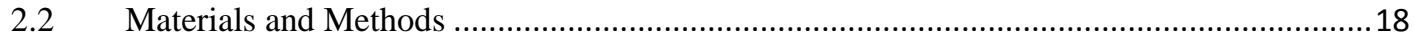

$\mathrm{H}$. iris collection and holding ............................................................................................18

Sediment analysis and concentration......................................................................................19

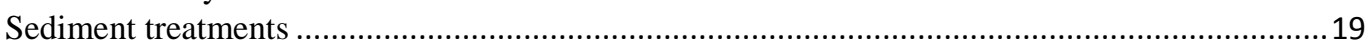

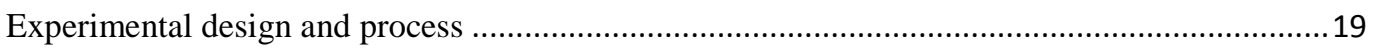

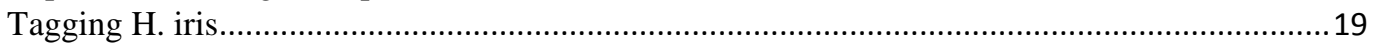

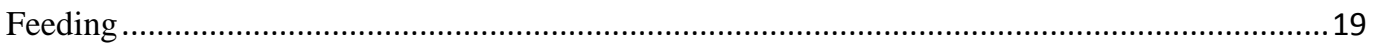

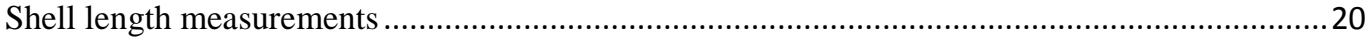

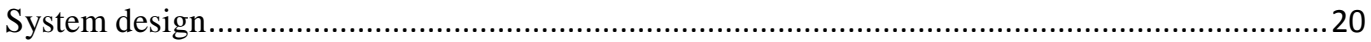

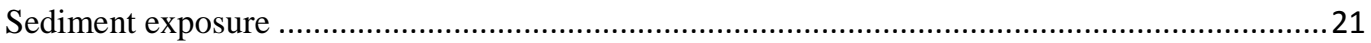

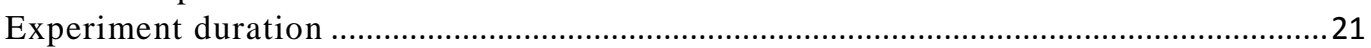

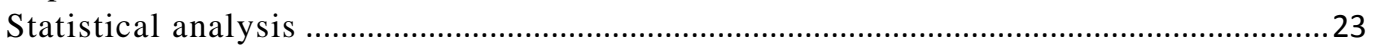

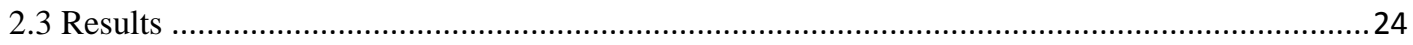

Sediment grain size and heavy metal analysis ................................................................

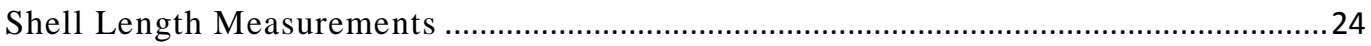

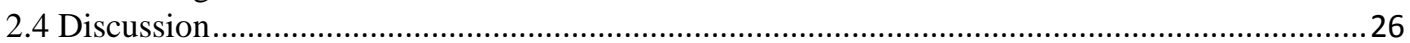

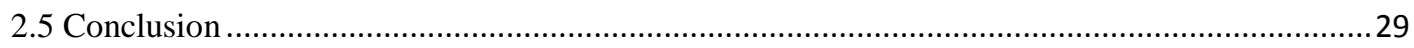

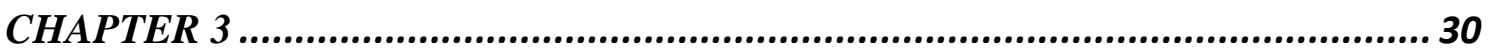

The Effect of Suspended Sediment on Oxygen Consumption in the Black Foot Abalone,

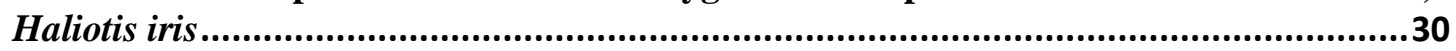

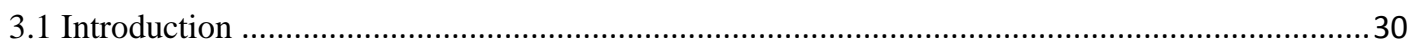

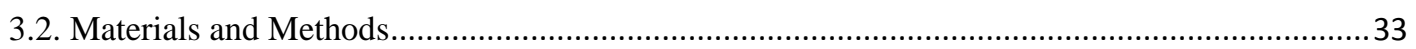

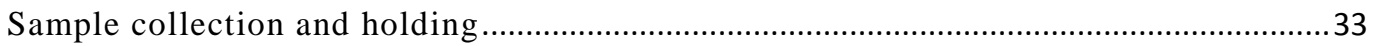

Sediment collection and composition ................................................................................

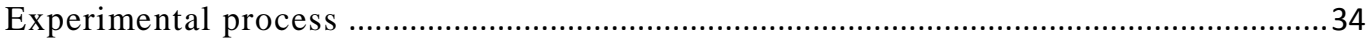

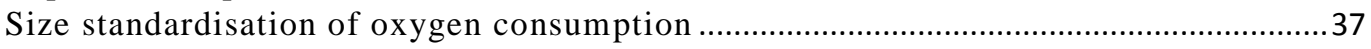

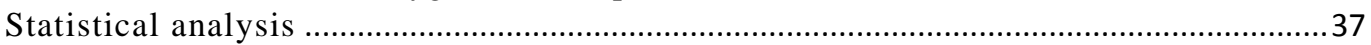

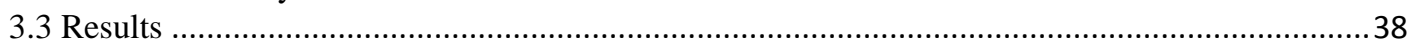

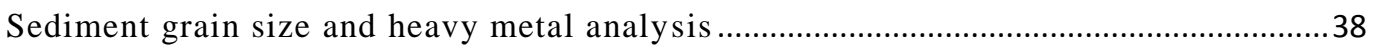

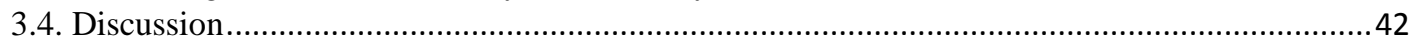

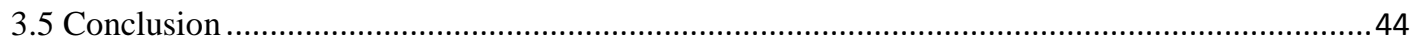

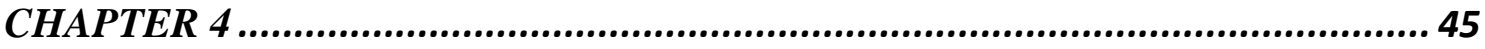


The Effect of Suspended Sediments on the Mucus Production in the Black Foot Abalone, Haliotis iris ......................................................................................................45

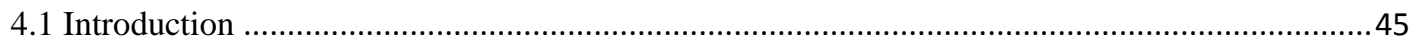

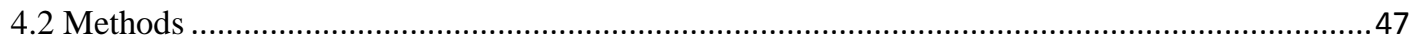

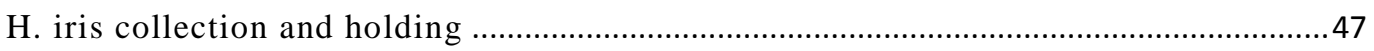

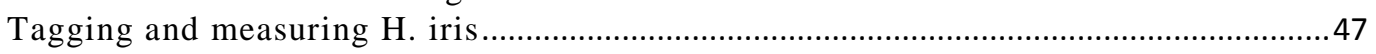

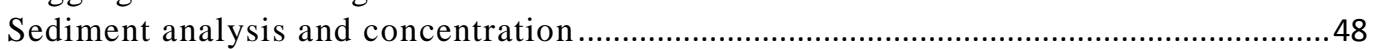

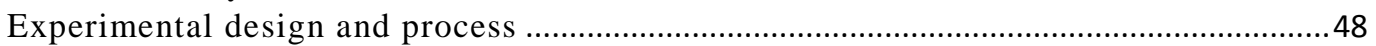

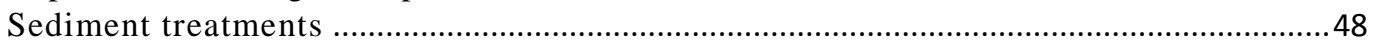

Mucus production \& Filtering .................................................................................. 49

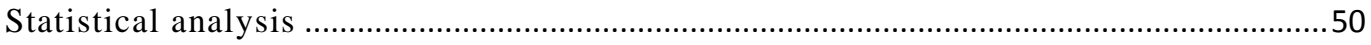

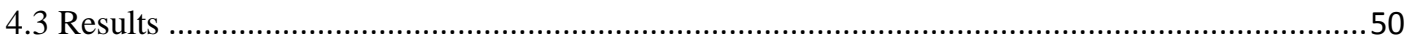

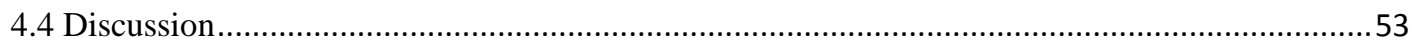

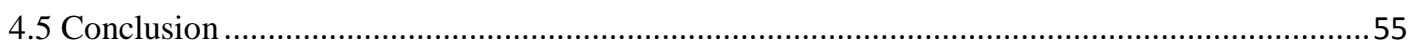

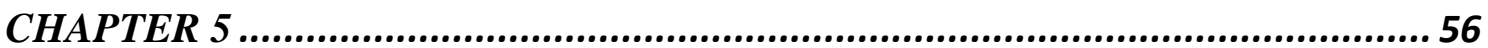

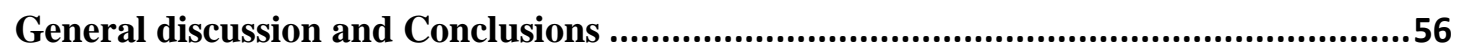

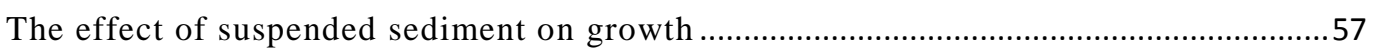

Does suspended sediment affect respiration? …………………….................................57

The effect of suspended sediment on mucus production ..................................................57

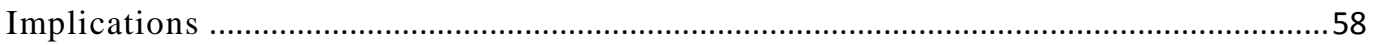

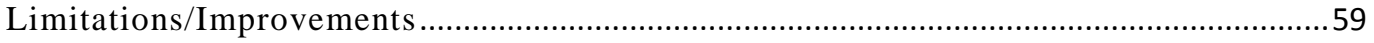

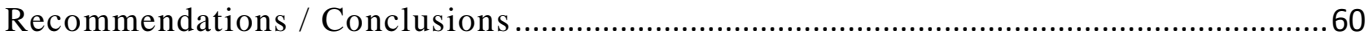

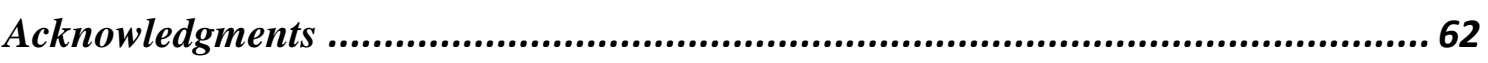

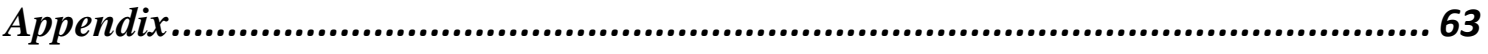

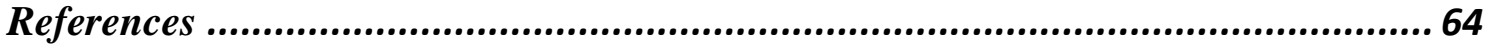




\section{List of figures}

Figure 2.1 Experimental set-up:

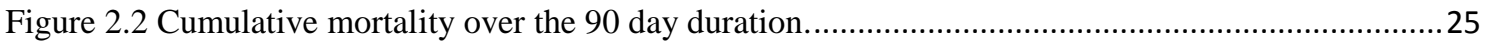

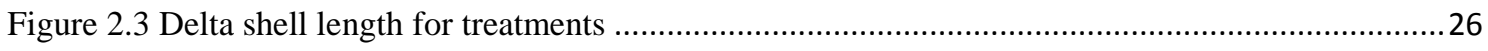

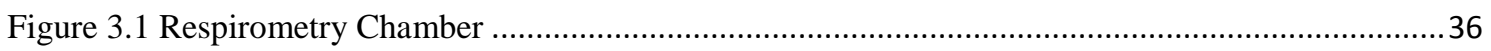

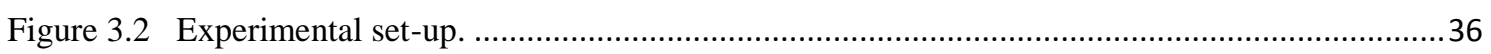

Figure 3.3 Average water bath temperature $\left({ }^{\circ} \mathrm{C}\right)$ for each treatment (Control, $2 \mathrm{X}$ and $\left.4 \mathrm{X}\right)$. ...................39

Figure 3.4 Average VO2s (standardised for dry weight) consumption of H.iris across treatments (Control,

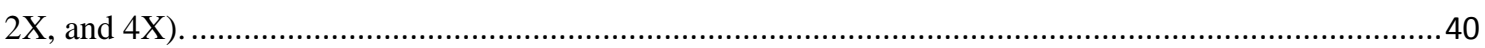

Figure 3.5 Linear relationship between VO2 (mgL-1) as a function of dry body weight $(\mathrm{g})$, for each treatment (Control, $2 \mathrm{X}$ and $4 \mathrm{X}$ ).

Figure 4.1 Average mucus production (g) (standardised by dry weight) for H. iris for treatments (control, $2 \mathrm{X}$ and $4 \mathrm{X})$. 51

Figure 4.2 Linear regression between Dry weight $(\mathrm{g})$ as a function of mucus production $(\mathrm{g})$, for each treatment (Control, $2 \mathrm{X}$ and $4 \mathrm{X})$....... 


\section{List of Tables}

Table 2.1.Food, sediment and cleaning schedule for H.iris over a week................................... 23

Table 2.2 Results of heavy metal analysis carried out by Environmental Laboratory Services. 24

Table 2.3 Mean initial shell lengths for each treatment with 95\% confidence intervals............ 25

Table 3.1 Results of heavy metal analysis carried out by Environmental Laboratory Services . 38

Table 4.1 Results of heavy metal analysis carried out by Environmental Laboratory Services. 50 


\section{CHAPTER 1}

\section{The effects of suspended sediment on the black foot abalone Haliotis iris}

\subsection{Sedimentation in the Marine Environment \\ Rocky shore habitats}

Rocky shores are harsh environments and one of the most extensive seaside habitats on wave-exposed coasts (Airoldi 1998). Rocky shores are subject to a variety of stressors (emersion in air due to tides, and wave action), (Crowe et al. 2000; Raffaelli et al. 2003) and as with other ecological systems, are increasingly under significant human pressure, including toxic pollution (e.g. mercury through burning of fossil fuels, waste incineration and mining)(Phillips 1977), eutrophication (e.g. from fertilizer run off) (Nixon 1995), habitat fragmentation (habitat alteration from land based activities e.g. agriculture and forestry) and sedimentation (Hughes et al. 2005).

\section{Sedimentation}

Sedimentation is the process that occurs once sediment enters waterways (McKee et al. 2004). In general terms, the adverse environmental effects resulting from this process are the smothering of aquatic flora and fauna (Newcombe \& MacDonald 1991). The most significant influences on sedimentation are the slope, soil type (poorly drained soils), and the use of land (used for pasture) which equates to high sediment yields (Hume et al. 2010). Suspended sediment is a primary determinant of light penetration and attenuation with the magnitude of the effect determined by the particle size and concentration (Townsend \& Thrush 2010). Turbidity has detrimental effects on water quality, and increased turbidity is been found to affect invertebrate density, invertebrate biomass (Henley et al. 2000) and result in losses in habitat structure (Short \& Wyllie-Echeverria 1996).

\section{Effects of sediment on marine organisms}

Suspended sediment can lead to alterations in the environment of marine organisms, including reduced visibility, and changes to the stratification of heat in the water column (Wilber \& Clarke 2001). Suspended sediment discharged into the near shore 
water column can alter the presence and distribution of many organisms including; micro and macroalgal, sea grass, bivalves, gastropods and molluscs (Fabricius 2005).

Sedimentation can have adverse effects on many marine organisms, with impacts on associated fauna including clogging of the gills of filter feeders (e.g. cockles, pipi, scallops) (Newcombe \& Jensen 1996), reduction in settlement success (Phillips \& Shima 2006), reduction in visual foraging efficiencies for salmon and diminished osmoregulatory abilities of fishes (Au et al. 2004). Newcombe and Jensen (1996) identified that with increased suspended sediment there was reduced growth in estuarine fish. An experiment by Rogers (1990) found heavy sedimentation significantly reduced coral growth, with calcification rates also decreasing. A study by Cheung and Shin (2005) found there was damage to the gills of green lipped mussels (Perna vividis) caused by acute exposure to suspended sediment, with a linear relationship between suspended solid concentrations and damage to gill filaments. However Cheung and Shin (2005) also found that ion regulating enzymes were affected when the gills of green-lipped mussels were abraided by suspended solids.

Steger and Gardner (2007) found no effect of suspended sediment on the oxygen consumption of the crab Petrolisthes elongatus, but they did find physiological effects e.g. clearance rate was lowest at high sediment concentrations when total particulate matter was greater than $1000 \mathrm{mg} \mathrm{L}^{-1}$, which resulted in a lower absorption efficiency. They suggested that such short term effects could significantly decrease growth rates, as less energy will be directed to growth.

\section{Sedimentation in New Zealand}

Coastlines are at the interface between oceans and land, and comprise a variety of rock and sediment types (Dawe 2007). New Zealand's landmass is highly diverse and easily eroded, which, in combination with active tectonic plates, and strong storm and rainfall events, results in vast amounts of sediment entering New Zealand's marine environment (Morrison et al. 2009). Since human settlement, two thirds of forest cover has been removed, causing severe and widespread erosion, sedimentation and flooding (Wright 2012). Land-based activities from industries such as agriculture and forestry, have resulted in sedimentation being the most 
significant land-based stressor on the coastal environment (Carter 1975). This includes both suspended and deposited loads (Morrison et al. 2009). Since European arrival in New Zealand, settlements have been established in low lying areas around the coast (Wardle 1991). However, the development of settlements in these areas has implications for marine life (Dawe 2007). New Zealand produces 200 million tonnes of sediment annually that washes down New Zealand rivers and into the sea (Wright 2012). Griffiths and Glasby (1985) estimated South Island sediment yields of $284 \pm 40 \times 10^{6}$ tonnes per year from a land area of $132,977 \mathrm{~km}^{2}$, and North Island yields of $105 \pm 9.4 \times 10^{6}$ tonnes per year from a land area of $114,621 \mathrm{~km}^{2}$. Highest rates were noted off the West coast of the South Island and East coast of the North Island. Increased sediment loads deposited into the coastal marine environment as a result of catchment development have been recognised as one of the most important marine contaminants in New Zealand (Ellis et al. 2002).

Excessive rates of sedimentation have also been seen in New Zealand harbours. For example, within the Porirua Harbour sediment is filling the harbour, smothering and harming plant and shellfish life and threatening future recreational use (Blaschke et al. 2009). Historical reclamations, road and railway structures have contributed to the destruction of significant plant species, leading to excessive sediment loads into the Harbour. Severe sedimentation reduces the ability for the harbour to flush itself or 'self cleanse' and because of this, sedimentation rates are likely to increase (Robertson \& Stevens 2010). The main sources of sedimentation into New Zealand's harbours are erosion-prone rural land, badly managed urban development and contaminants (Townsend \& Thrush 2010).

\subsection{Abalone}

Haliotis species, commonly known as abalone, are a distinct group of marine archeogastropods that live in a range of sheltered and exposed shallow coastal marine habitats (Wells et al. 1998), they are distributed in temperate and tropical regions throughout the globe (Naylor et al. 2006). Abalone are sedentary marine invertebrates commercially harvested for their valuable meat and shell. Major commercial fisheries exist or have existed, in various countries including; Australia, South Africa, Mexico, Japan, United States, New Zealand, Korea, Taiwan, Philippines, China, Chile, France and Thailand (Shepherd et al. 1992). 
In recent years abalone fisheries have become unsustainable and have either declined significantly or have been closed due to over exploitation, excessive poaching and outbreak of diseases (Gordon \& Cook 2013). Abalone populations are under considerable threat worldwide as they are sedentary marine invertebrates. This makes them prone to serial depletion, reduced recruitment and over-fishing (Gordon \& Cook 2013). On top of fishing pressure, there are also other human impacts such as sedimentation. Sedimentation has negative effects on other marine species (Morrison et al. 2009). However there have been few studies that have examined the effects of sediment on abalone. Onitsuka et al. (2008) found that the larval metamorphosis rate of Haliotis diversicolor was significantly lower for those larvae that were subject to elevated sediment levels, and also found that sedimentation clearly inhibited larval settlement on the substratum. Their results indicate that physical properties of sediment, such as stickiness, and grain size are important factors in determining settlement behaviour of $H$. diversicolor .

\section{Haliotis iris}

Haliotis iris, commonly known as the black foot pāua, is the largest of the Haliotid species living within New Zealand waters. H. iris have pelagic larvae (Roberts \& Lapworth 2001), with a larval stage of 4-8 days depending on temperature, and reach settling competence at 5-9 days (Moss et al. 1995). H. iris can reach maximum shell lengths of $180 \mathrm{~mm}$ and can live up to 50 years of age (McShane \& Naylor 1995), and is found in both the sub-littoral fringe and sub-tidally on hard substrata, throughout the coastal areas of New Zealand (Chew et al. 2013). Most wild $H$. iris are commercially fished from the South Island, Chatham Islands, Stewart Island and the Southern Coast of the North Island (Di Leva 2013). A number of $H$. iris stocks have been depleted in Stewart Island (Pāua fisheries Management area 5B) and some parts of Southland (Pāua fisheries management area 5A) (Eggert \& Kahui 2013).

\subsection{Haliotis iris and sediment}

There is little quantitative information on whether land based-effects directly impact adult populations of $H$. iris, although Phillips and Shima (2006) looked at the effects of suspended sediment loads on both urchin, Evechinus chloroticus, and H. iris 
larvae and found mortality rates for both increased in response to acute exposure to sediments in early development stages. Urchin mortality was immediate and ceased once the stressor was removed, indicating their larval stage is more vulnerable to cumulative effects of sediment then urchins (Phillips \& Shima 2006). McShane and Naylor (1995) noted that juvenile $H$. iris were generally absent from exposed coastlines. Schiel (1995) suggested this was caused through the lack of adequate inshore rock habitats. Schiel (1995) noted how high energy turbulence caused sedimentation, which in turn may cause significant post-settlement mortality. There are yet to be studies on the direct impacts of sedimentation on juvenile and adult populations of $H$. iris.

Chew et al. (2013) tested the likely effect of dispersed sediments on the behaviour and mortality of $\mathrm{H}$. iris and found that there was no mortality and no adverse effects on their health. However $H$. iris avoided sediments by moving from predation refugia (under cobbles) to more exposed areas where they were more vulnerable to predation. Deposited sediments also inhibited the righting response of $H$. iris, which is an important behaviour for re-attachment after dislodgement (Chew et al. 2013).

Increases in sedimentation due to elevated runoff into coastal areas can lead to alterations in community structure (Aguirre \& McNaught 2012), with the loss of important grazer species such as $H$. iris, potentially allowing opportunistic algal species to flourish e.g. Ulva species. H. iris is sensitive to slight changes in environmental conditions (e.g. water temperature, light intensity and wave exposure)(Vilchis et al. 2005), which can affect local populations by stunting growth, and lead to migration to cooler waters (Day et al. 2001).

There have been limited studies examining the effects of sediment on $H$. iris in New Zealand. Other studies on abalone species, throughout the world have focussed on larval survival and settlement, or the effects of deposited sediment on adult behaviour (Phillips \& Shima 2006; Onitsuka et al. 2008; Chew et al. 2013). However there are large gaps in the research around the effects of suspended sediment on $H$. iris specifically. Although Ragg (2003) suggested that sediment may result in increased metabolic cost via mucus production in $H$. iris, no work has been carried out on this to date. Similarly, no-one has examined the effect of suspended sediment on the growth of $H$. iris, even though it comprises a high value 
commercial, customary and recreational fishery, and sedimentation is the most significant land-based effect on the marine coastal environment in New Zealand To advance our understanding of the effects of suspended sediment on the abalone, Haliotis iris, my thesis is structured as follows:

\subsection{Thesis Structure}

Chapter 2: The effect of suspended sediment on the growth of Haliotis iris Chapter 2 investigates the effect of suspended sediment on growth of juvenile Haliotis iris, using sediment concentrations typically found after heavy rainfall within Wellington Harbour. Three treatments were used; control, low and high sediment loads. Sediment was pulsed every 2-3 days and growth was measured every four weeks for 12 weeks. Growth was then compared between treatments.

Chapter 3: The effect of suspended sediment loads on the oxygen consumption of juvenile Haliotis iris.

Chapter 3 looks at the effects of suspended sediment loads on the oxygen consumption of Haliotis iris. Sediment concentrations were based on amounts within Wellington Harbour after heavy rainfall. The rate of oxygen consumption for H. iris was measured under three sediment treatments (similar to chapter 2); control (no sediment), low, and high sediment loads. Oxygen consumption was then compared between treatments.

Chapter 4: The effect of suspended sediment loads on the mucus production of Haliotis iris.

Chapter 4 examines the effect of suspended sediment loads on the mucus production of $H$. iris, by exposing $H$. iris to suspended sediment concentrations typically found in the Wellington Harbour after heavy rainfall for duration a of 24 hours. Mucus was then measured and compared between treatments.

\section{Chapter 5: General Discussion and Conclusions}

Chapter 5 provides an overall summary and discussion of the implications of my findings for Haliotis iris, and abalone in general. 
Chapters 2, 3, and 4 are written as stand-alone chapters. As a consequence, there is some repetition relating to the background knowledge around sediments used in the experiments examining: the effect of suspended sediment on the growth, oxygen consumption and mucus production of Haliotis iris. 


\title{
CHAPTER 2
}

\section{The Effect of Suspended Sediment on the Growth of the Black foot Abalone, Haliotis iris.}

\begin{abstract}
Sedimentation is the most important land-based stressor in New Zealand. Rocky coast habitats are under considerable threat due to urban development, large scale forest clearances, pastoral livestock, farming and forestry. All of these contribute to the vast amounts of sediment into the marine environment. Effects on marine organisms include; clogging of the gills of filter feeders, decreased filter feeding ability and reductions in settlement success. H. iris is a valuable commercial, recreational and customary fishery in New Zealand, but little is known about the effect of suspended sediment on their growth. This study investigated the effects of suspended sediment on the growth of the black foot abalone, Haliotis iris over 87days. H. iris growth (change in shell length) was measured under varying sediment loads (Control, 2X ambient and $4 \mathrm{X}$ ambient). There was no effect of suspended sediment on the growth of $H$. iris but there was a non-significant trend of increased growth in the control treatment. Sediment concentrations used in this study are relatively low in comparison to those found in situ and in other areas around New Zealand. It is suggested that exposure to higher concentrations for longer durations could possibly produce different results for $\mathrm{H}$. iris, and provide valuable information to manage land-based effects on important abalone fisheries.
\end{abstract}

Key words: Abalone, Growth, Sediment, New Zealand, Haliotis iris.

\subsection{Introduction}

Coastal marine systems have experienced drastic change over a short period of time, with anthropogenic activities being the primary cause for these changes (Steckbauer et al. 2011). Global increases in urban development to accommodate an expanding population have been a major source of disturbance in marine systems. Sedimentation is 
one of the main land-based impacts on coastal marine ecosystems (Morrison et al. 2009). Urban development, large-scale forest clearances, expansion of land-based industries for pastoral livestock, farming, exotic forestry plantation and dredging, have all contributed to increased sediment loads that are being deposited into the marine environment (Chin 2006). Rocky coast habitats are some of the most vulnerable to deposition of sediment (Airoldi 1998).

Sedimentation is the most important land-based stressor in New Zealand (Morrison et al. 2009). Sedimentation impacts include a decrease in water clarity, that directly impacts species like filter feeders by clogging their gills (Ryan 1991). Other sedimentation impacts are, reductions in settlement success (Hodgson 1990), and reduced foraging ability of many fin fish (Kemp et al. 2011).

Abalone are marine gastropods belonging to the genus Haliotis, and are herbivores. They are commonly found in shallow coastal waters, and prefer to graze on red or brown algae (Tyler 2012). New Zealand has three endemic species of abalone, all commonly referred to as 'pāua'. The largest, and most common, is Haliotis iris and is highly valued, supporting important commercial, customary and recreational fisheries (Statistics New Zealand, 2010). H. iris can reach maximum shell lengths of $180 \mathrm{~mm}$ and can live up to 50 years of age (McShane \& Naylor 1995). Growth in H. iris is asymptotic (rapid growth in early ages then slows down after maturation) (Shepherd \& Hearn 1983), but growth rate and maximum size is highly variable around New Zealand (Naylor et al. 2006).

New shell growth in gastropods and molluscs, occurs at the aperture end of the shell (Vermeij \& Signor 1992). This allows a near complete record of growth from time of hatching to death (Vermeij \& Signor 1992). Previous studies on growth of gastropods have been mainly focussed on temperature conditions, spawning, fertilisation, larval growth and maturation (Dehnel 1955). Temperature is a major determinant of metabolic rate, which can directly affect growth rate in abalone (Searle et al. 2006). Abalone exposed to cooler waters tends to grow at a slower rate, and reach larger overall asymptotic growth. Juveniles exhibit rapid growth, which slows as they age. Other factors also affecting the growth rate of abalone include water flow (Fleming et al. 1997), water quality (Leitman 1992), salinity (Wickins 1981), stocking density (Koike 
et al. 1979), feeding regime (Hooker \& Morse 1985) and nutrition in cultured populations (Creese \& Underwood 1982). In wild populations growth can be affected through the availability of food, with decreased growth attributed to low food (Creese \& Underwood 1982). However, few studies have focused on natural growth rates on a single species (Poore 1972; Prince et al. 1988; Lebel et al. 1996).

Exposure to sediments has been shown to elicit disparate responses in marine organisms, including varying effects on growth. For example, blue mussels (Mytilus edulix), surf clams (Spisula subtruncata), and eastern oysters, exhibited increased growth, in high algal concentrations, after the addition of silt (Wilber \& Clarke 2001). However, Northern quahogs (Mercenaria mercenary) and eastern oysters exposed to sediment with high silt and clay content exhibited reduced growth, lower survival, and sub-lethal effects such as reduced pumping rates and growth (Rogers 1990; Wilber \& Clarke 2001).

With sedimentation being one of the biggest human impacts on the coastal zone in New Zealand (Morrison et al. 2009). H. iris populations can be subject to both suspended and deposited sediments. However, the literature on the effects of sediment on growth in abalone is very limited. Onitsuka et al. (2008) found initial densities of the abalone, Haliotis diversicolor, were low when large amounts of sediment were found on the substratum. However, they did not examine growth in relation to the presence of sediments. This chapter aims to describe the potential effects of suspended sediment on the growth of juvenile $H$. iris in culture.

\subsection{Materials and Methods}

\section{$H$. iris collection and holding}

Experiments were conducted at VUCEL (Victoria University Ecology Laboratory) between April and August 2013. H. iris were provided by OceaNZ Blue (Ruakaka, Northland, New Zealand). H. iris were delivered to VUCEL on 16th of March, and placed in holding tanks containing free-flowing filtered seawater pumped from the coastal waters of Cook Strait. Tanks were covered with corrugated white plastic (corflute), to keep light exposure to a minimum. H. iris was fed at 2-3 day intervals on 
crushed dry stored feed AbMax (E.N. Hutchinson Ltd, Auckland, NZ). Remaining food and faecal matter were removed from tanks with a siphon prior to feed re-stocking. Artificial turf was glued to the edge of each holding tank to prevent $H$. iris from escaping (the texture of the grass irritates the foot). Over-flow pipes were also covered with mesh to prevent small $H$. iris from escaping. Small cobbles were also placed in the tanks (for $H$. iris to attach to).

\section{Sediment analysis and concentration}

Suspended sediment concentrations used in the experiment were based on those used by Phillips and Shima (2006), which were based on concentrations found after heavy rainfall in Wellington Harbour. Sediment used was collected from Lake Ferry, Wairarapa on the $16^{\text {th }}$ August 2011. Grain size analysis was carried out by the School of Geography and Environment and Earth Sciences at Victoria University of Wellington, using a laser particle sizer. Sediment was analysed for heavy metals by Environmental Laboratory Services (ELS) in Seaview, Lower Hutt.

\section{Sediment treatments}

Treatments for the experiment included control (no sediment), 2X Ambient $(100 \mu \mathrm{m}$ filtered seawater with $0.029 \mathrm{~g} \mathrm{~L}^{-1}$ of sediment added) and $4 \mathrm{X}$ Ambient (100 $\mu$ filtered seawater with $0.058 \mathrm{~g} \mathrm{~L}^{-1}$ of sediment added). There were 10 replicate containers holding 5 individuals for each treatment, giving, in total 150 juvenile $H$. iris.

\section{Experimental design and process}

\section{Tagging H. iris}

H. iris were tagged with bee tags (Ceracell Queen marking numbered kit; Product code: QMK0055) that were numbered so that each individual could be identified for individual growth measurements. Bee tags were glued on the shells using super glue (Gorilla Super Glue Ultra-Bonder Power Liquid; Product no: 41344).

\section{Feeding}

During the experiment, $H$. iris was fed crushed artificial feed (AbMax). The amount of food given to $H$. iris was a predetermined amount which was $40 \%$ of their body weight per day (Viera et al. 2005). Each H. iris was given in excess of two days' worth of food 
(0.35 g) per replicate container (i.e. per five individuals in container). Feeding was repeated every 2-3 days.

\section{Shell length measurements}

The shell length of each animal was measured to the nearest $0.01 \mathrm{~mm}$ using steel vernier callipers. Shell length was measured at the start of the experiment and then every four weeks for three months. To ensure shell length measurements were accurate, a New Zealand 20 cent coin was measured with steel vernier-callipers. This measurement was taken ten times. An H. iris shell that was of similar size of those used in the growth experiment was also measured ten times. The mean and standard error were calculated for both the 20cent coin and the H. iris shell, along with a measure of precision and the coefficient of variation (see appendix A).

\section{System design}

H. iris were then placed in $565 \mathrm{ml}$ cylindrical plastic containers (Tekpac Industries T303 - Tub, 565/110 MTE) containing $400 \mathrm{ml}$ of flow-through filtered sea water i.e., five animals per replicate container. The containers were covered in black duct tape so that $H$. iris were in a dark environment. Sticky dots (Velcro spots Hook 22mm spots white) were placed underneath the containers and stuck to the sea table, so that the paddles didn't move the containers. To prevent the H. iris from escaping, the lids of the containers had the middle cut out of them and a sticky paste (tangle foot) was spread on the rims of the containers; the sticky paste irritates the foot of $H$. iris. Each container also had 20 holes located approximately $2 \mathrm{~cm}$ from the top edge for drainage and to keep the water level consistent. This also prevented $H$. iris from escaping. As juvenile $H$. iris is photosensitive, the whole experimental structure was also covered with black plastic to reduce light exposure as much as possible.

Plastic paddles were placed in each replicate container, with the paddles suspended from wooden racks that moved backwards and forwards every second. Silicone air hoses (Blue planet Bubilo air hose 4mm; Product no: EF008) had small pinholes drilled where attached to the bottom of the paddles and connected to a pump with constant air flow. This kept sediment suspended at all times. The experimental apparatus is shown in Figure 2.1. 


\section{Sediment exposure}

For the first week of the experiment, no sediment was added to the replicate containers to reduce the stress on $H$. iris. After week 1, sediment treatments were pulsed twice per week, with $H$. iris exposed to the sediment treatment for a 24 hour period. The air bubbler attached to the paddles ensured that sediment could be kept in suspension (Fig. 2.1). When $H$. iris were exposed to the sediment treatment, the water supply was turned off and they were also fed with artificial feed. After the 24 hour sediment exposure, containers were thoroughly washed so there was no remaining sediment left in the containers. Food was also replaced at this time and containers were put back in the same place and water turned back on. The air pump was left on for the duration of the experiment to keep water oxygenated (Table.2.1).

\section{Experiment duration}

The growth experiment ran for 87 days, from April to July 2013, with measurements of shell length made approximately every 4 weeks. Prior to measurement, $H$. iris were inspected to check the individuals for shell cracking and mortality. 
a
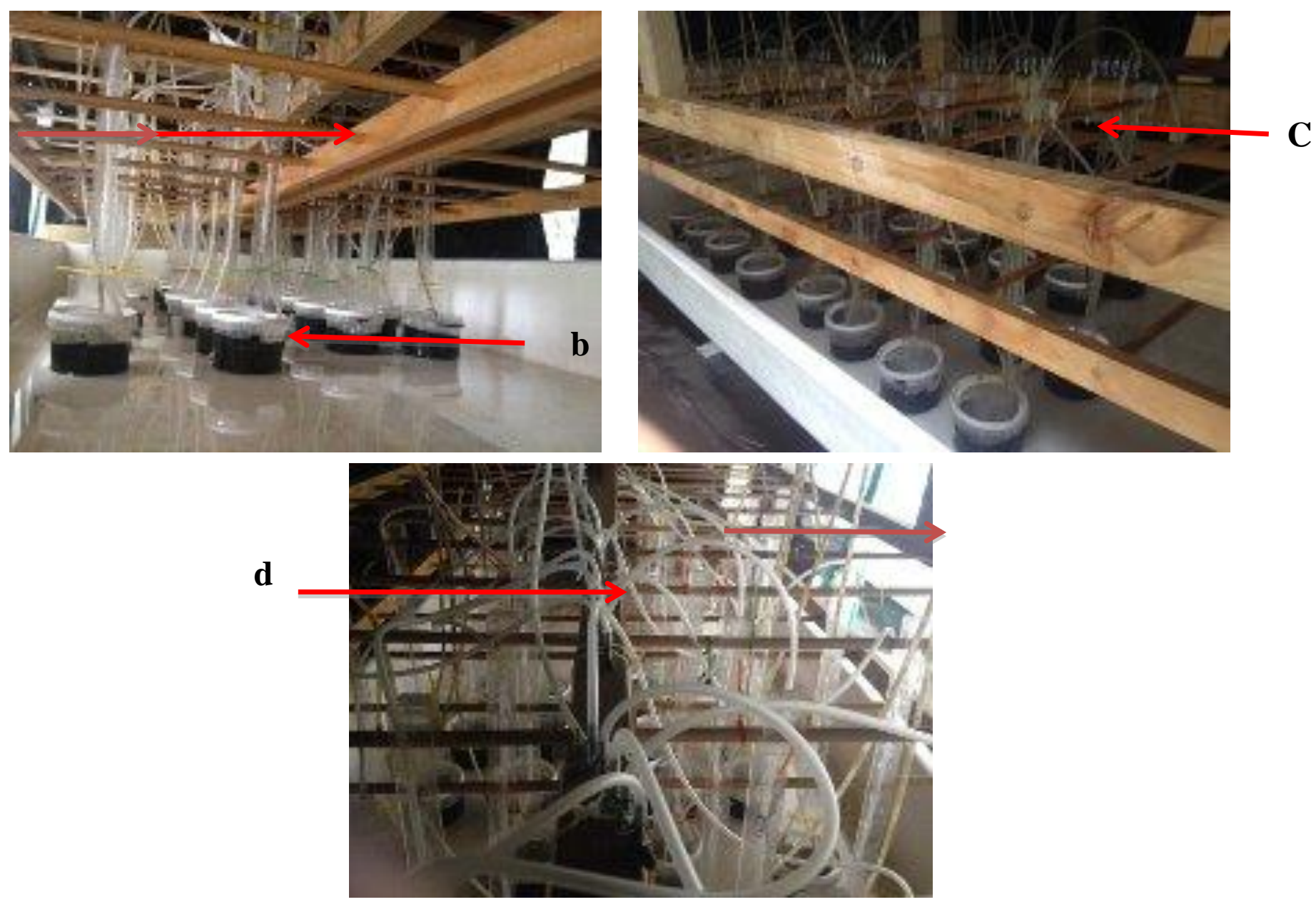

Figure 2.1 Experimental set-up: (a) wooden rack system (b) replicate plastic containers (c) plastic paddles suspended from wooden rack system (d) air and water transferred into plastic containers through silicon air hose. 
Table 2.1.Food, sediment and cleaning schedule for H.iris over a week.

\begin{tabular}{|l|l|l|l|l|l|}
\hline \multicolumn{1}{|c|}{ Week day } & \multicolumn{1}{c|}{ Sediment and food } & \multicolumn{1}{c|}{ Water } & \multicolumn{1}{c|}{ Food } & \multicolumn{2}{c|}{ Cleaning } \\
\hline Monday & $\begin{array}{l}\text { Water turned off and food and sediment } \\
\text { added }\end{array}$ & Off & Yes & Yes & On \\
\hline Tuesday & $\begin{array}{l}\text { Water turned on sediment and faecal matter } \\
\text { removed. Food added }\end{array}$ & On & Yes & Yes & On \\
\hline Wednesday & Water left on, no food or sediment added & On & No & No & On \\
\hline Thursday & $\begin{array}{l}\text { Water turned off and food and sediment } \\
\text { added }\end{array}$ & Off & Yes & Yes & On \\
\hline Friday & $\begin{array}{l}\text { Water turned on sediment and faecal matter } \\
\text { removed. Food added }\end{array}$ & On & Yes & Yes & On \\
\hline Saturday & Water left on, no food or sediment added & On & No & No & On \\
\hline Sunday & Water left on, no food or sediment added & On & No & No & On \\
\hline
\end{tabular}

\section{Statistical analysis}

Differences in mean initial shell length between treatments were tested using one-way ANOVA. No data transformations were done for any of the shell length data prior to statistical analysis since assumptions of normality and equal variances were met. Per capita mortality was calculated at each monthly interval by dividing the number of dead individuals per replicate by the total number of individuals per replicate at the start of the monthly interval, and then dividing by the number of days in the monthly interval. The per capita mortality data was square-root-arcsine transformed prior to analysis. For each treatment, change in shell length (delta shell length) at each approximately 4 week interval over the course of the experiment was calculated as shell length at end of month - initial shell length at start of the experiment, divided by the number of days since the experiment started. However in a few treatments, some H. iris died, so mean growth rates in these treatments were computed for all remaining $H$. iris. Differences between treatments for raw shell length data, which were recorded at the start of the experiment and at each monthly interval until the end of the experiment to assess $H$. iris growth, were analysed using repeated measures ANOVA. Differences between treatments for per capita mortality were also assessed using repeated measures ANOVA. Repeated measures ANOVA was used for the shell length and per capita mortality data as the same group of individuals were repeatedly measured over a period of 87 days. 
Assumptions underlying repeated measures ANOVA include homoscedasticity of variances and normally distributed residual variation and sphericity (Sokal \& Rohlf 1981). The raw shell length data violated Mauchly's assumption of sphericity for repeated measures ANOVA, so this was corrected by using the Huynh-Feldt correction since epsilon was greater than 0.75 . Per capita mortality did not violate Mauchly's assumption of sphericity, so no corrections were made. All of the above analyses were carried out using the statistical package SPSS (SPSS 2011). A critical alpha level of 0.05 was used for all statistical tests.

\subsection{Results}

\section{Sediment grain size and heavy metal analysis}

Total sediment grain size composition comprised $68.15 \%$ Silt, $29.09 \%$ sand and $2.76 \%$ clay.

Table 2.2 Results of heavy metal analysis carried out by Environmental Laboratory Services.

\begin{tabular}{|l|l|l|l|}
\hline Test & Detection limit & Results & Units \\
\hline Arsenic-Total & $0.05 \mathrm{mgKkg}$ & 4.30 & $\mathrm{Mg} / \mathrm{Kg}$ \\
\hline Cadmium-Total & $0.01 \mathrm{mg} / \mathrm{Kg}$ & 0.01 & $\mathrm{Mg} / \mathrm{Kg}$ \\
\hline Chromium-Total & $0.2 \mathrm{mg} / \mathrm{Kg}$ & 26.2 & $\mathrm{Mg} / \mathrm{Kg}$ \\
\hline Copper-Total & $0.3 \mathrm{mg} / \mathrm{Kg}$ & 8.8 & $\mathrm{Mg} / \mathrm{Kg}$ \\
\hline Lead-Total & $0.1 \mathrm{mg} / \mathrm{Kg}$ & 10.1 & $\mathrm{Mg} / \mathrm{Kg}$ \\
\hline Nickel-Total & $0.2 \mathrm{mg} / \mathrm{Kg}$ & 19.7 & $\mathrm{Mg} / \mathrm{Kg}$ \\
\hline Zinc-Total & $1 \mathrm{mg} / \mathrm{Kg}$ & 57 & $\mathrm{Mg} / \mathrm{Kg}$ \\
\hline
\end{tabular}

All results analysed by ICPMS or ICPOES are reported in dry weight basis

Heavy metal analysis results showed that heavy metal concentrations were well below the Australian and New Zealand Environment Conservation Council Sediment Quality Guideline (2000) trigger values and the Auckland Regional Council Environmental Response Criteria (2004) thresholds (See Stephenson et al. 2008 for further detail).

\section{Shell Length Measurements}

Shell length measurements had a very good level of precision for both the 20 cent coin and the $H$. iris shell $(P=0.0006$ and $P=0.0002$ respectively - see Appendix A) 
Table 2.3 Mean initial shell lengths for each treatment with 95\% confidence intervals.

\begin{tabular}{|l|l|l|l|}
\hline Treatment & Shell length (3dp) & 95\% CI (3dp) & $\boldsymbol{N}$ \\
\hline Control & 14.846 & 0.513 & 50 \\
\hline $\mathbf{2 X}$ & 15.119 & 0.50 & 50 \\
\hline $\mathbf{4 X}$ & 15.236 & 0.503 & 50 \\
\hline
\end{tabular}

Initial shell length was tested between treatments using one-way ANOVA. There wew no significant differences between initial shell length across treatments $\left(F_{1,147}=0.603, p\right.$ $=0.548)$. Average shell length of the $150 \mathrm{H}$. iris was $(15.14 \mathrm{~mm}+/-0.28 \mathrm{~mm}) 95 \% \mathrm{CI})$.

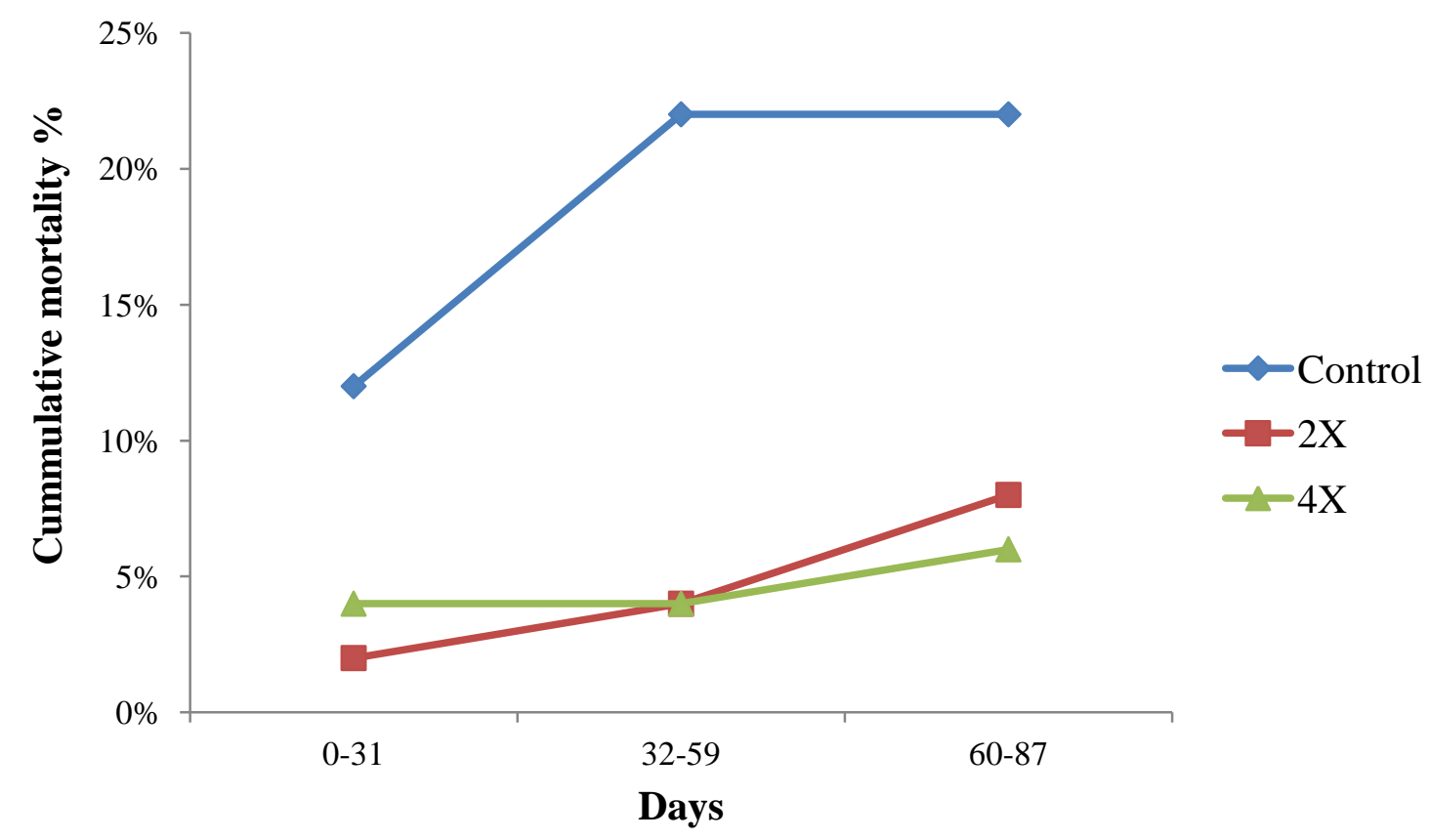

Figure 2.2 Cumulative mortality over the 90 day duration of the experiment expressed as a percentage of initial live $\mathrm{H}$. iris. Initial $\mathrm{n}=50$ for each treatment.

Over the duration of the experiment, the cumulative mortality of $H$. iris after 31 days was significantly higher in the control treatment (12\% mortality), with $2 \%$ mortality in the $2 \mathrm{X}$ treatment, and $4 \%$ in the $4 \mathrm{x}$ treatment. At the 87 day mark there was $22 \%$ cumulative mortality within the control treatment however $H$. iris in the $4 \mathrm{X}$ treatments only had $6 \%$ cumulative mortality (Fig 2.2). However, repeated measures ANOVA 
revealed there was no significant difference in per capita mortality rates between treatments (control, $2 \mathrm{X}$ and $4 \mathrm{X})\left(F_{2,25}=0.807, p=0.457\right)$.

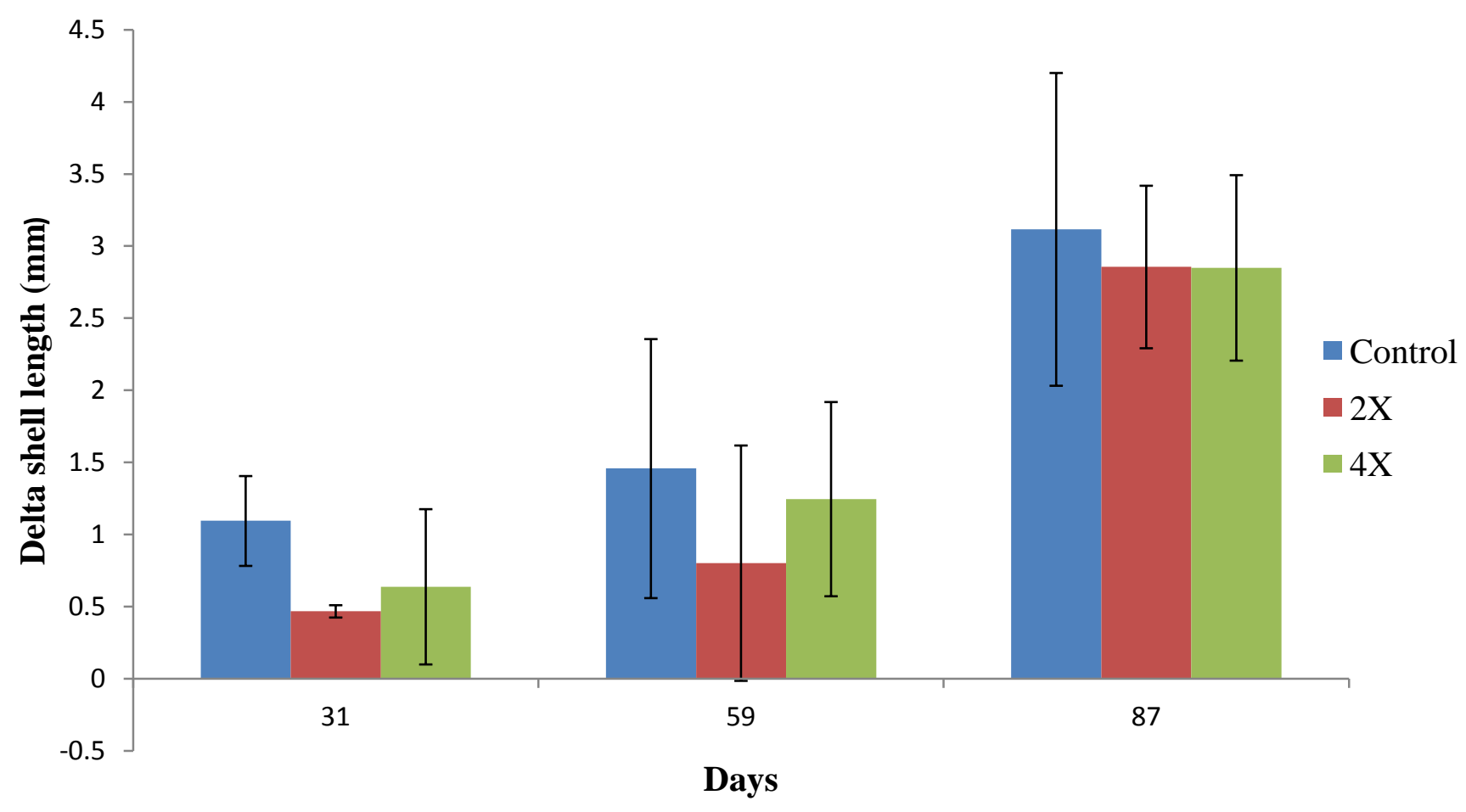

Figure 2.3 Delta shell length for treatments (control, $2 \mathrm{X}$ and $4 \mathrm{X}$ ) over experimental time (31, 59 and 87 days). Error bars represent $95 \%$ confidence intervals.

Mean change in shell length increased for all treatments over the 87 days and was highest in the control treatment, followed by the $2 X$ and $4 X$ treatments, which were similar to one another. Change in shell length for the $2 X$ treatment was less than the Control and $4 \mathrm{x}$ treatment at 59 days, but at 87 days it was similar to the $4 \mathrm{X}$ treatment (Fig. 2.3). However, the change in shell length was highly variable for the $2 X$ treatment at the 59 day mark with $95 \%$ confidence intervals bisecting the x-axis (Fig.2.3). Repeated measures ANOVA showed that there was no significant difference in mean shell length over time between sediment treatments $\left(F_{2}, 125=0.471, p=0.626\right)$. However, there was a significant effect of time on shell length $\left(F_{2.605,325.584}=155.635, p\right.$ $=<0.001)$ with increasing shell length over time for all treatments.

\subsection{Discussion}

There was no evidence in this study to suggest that growth is affected by suspended sediment. However, suspended sediment has been shown to affect early life-history 
stages of H. iris. A study by Phillips and Shima (2006) found suspended sediment causes larval mortality in H. iris, and Onitsuka et al.(2008) found the larval metamorphosis rate in $H$. diversicolor larvae was considerably lower in treatments with sediment, also inhibiting larval settlement. Previous studies on other marine organisms have found sediment can either have positive or negative effects on growth. Bricelj et al. (1984), found that growth rates of hard clams (Mercineria mercineria) were reduced as the clams responded by reducing their pumping rates and expending less energy into growth. Conversely, blue mussels (Mytilus edulis) exhibited increased growth rates when exposed to low sediment concentrations, through some mechanism that enhanced their filtering abilities (Kiørboe et al. 1981).

Haliotis species can have seasonal, as well as spatial, differences in growth rates between species, and within species (Naylor et al. 2006). Hooker et al. (1997), found that growth of $H$. iris was highly variable for individuals that were less than $25 \mathrm{~mm}$ in shell length. The annual growth varied from $450 \%$ to under $50 \%$ in such individuals. Individuals with shell lengths longer then $25 \mathrm{~mm}$ were less variable, and as shell length increased, growth slowed. Clarke (2001), also concluded that growth of H. iris less than $40 \mathrm{~mm}$ in length was highly variable. Such variability in growth rates between individuals could be one reason why it was difficult to detect any effect of sediment on growth in $H$. iris.

The size range used in this experiment may be resistant to potential effects of suspended sediment and another reason why growth rates were not statistically different between treatments. Sediment movement is a natural phenomenon that marine organisms have had to cope with for millennia (Miller et al. 2002). Our results were consistent with studies by Chew et al. (2013), who suggested that deposition of low levels of sediment (up to $1 \mathrm{~mm}$ ) are unlikely to cause mortality and morphological effects within juvenile H. iris. However, in their study, the presence of sediment did lead to altered behaviour, which could have significant indirect effects on wild populations (i.e. habitat modification and food availability). Similarly, the sediment levels used in our study were relatively low compared with levels experienced in other areas around New Zealand. New Zealand has one of the highest sedimentation rates in the world, due to land use change, urbanisation, forestry, and farming. Sediment concentrations used for this study are concentrations found within the Wellington Harbour after heavy rainfall, but these concentrations are low in comparison to other regions in New Zealand. The 
Bay of plenty has sedimentation rates 16 times higher $\left(0.928 \mathrm{~g} . \mathrm{l}^{-1}\right)$ than those used in the present study and, East Cape is 68 times higher (3.944 g. . $^{-1}$ ) (Morrison et al. 2009). If higher concentrations had been used in the study, this may have led to different observations surrounding the growth rates of $H$. iris. A study by Shin et al. (2002) on the green lipped mussel (P.viridis) demonstrated they can tolerate high concentrations of suspended solids without mortality. However they did see impairments in gill structure. They hypothesised that morphological damages to ctnedia (gills) could eventually reduce activities such as feeding, respiration, and growth over longer durations. Similarly, it may be that $H$. iris can tolerate the sediment levels used in this study, but further investigation is required into whether there was any morphological damage.

All H. iris in all treatments may have been under significant stress after handling and manipulation (i.e. shell measuring and transport into containers) which could account for the increased growth in the last month of the experiment (measurement at 87 days), which was significantly higher than measurements taken at 31 and 59 days. At day 31 and 59 days $H$. iris may have all been under significant stress (from handling) but at 87 days may have acclimated to the disturbance, and been less stressed, thus able to put more energy into growth. Maltby (1999) found that individuals that have been under significant stress have reduced energy intake for defence and repair processes.

During the experiment, Wellington also had a significant storm which cut off the seawater supply to the marine laboratory, with $H$. iris in the experiment having no supply for at least two days. During this time many of the control individuals died. This could be due to having a smaller average size than the rest of the treatments and being more vulnerable to disruptions, although size was not statistically different between treatments. However there was no significant difference between per capita mortality rates between treatments over the duration of the experiment. Hooper et al. (2011) showed that abalone are sensitive to movement and handling (when being transferred to different tanks) which causes stress and can have detrimental effects on growth, immune suppression and susceptibility to disease outbreaks.

The present study could be improved by increasing the number of replications and, using a smaller size range of $H$. iris. Extending the duration of the experiment and increasing the concentrations of suspended sediment used in each treatment would also be useful should any further work be carried out. 


\subsection{Conclusion}

This is the first study to investigate the potential effects of suspended sediments on the growth of $H$. iris, or for any abalone species. This study found that juvenile $H$. iris $(15.14 \mathrm{~mm}+/-0.28 \mathrm{~mm}) 95 \% \mathrm{CI})$ ) appear to be tolerant of low suspended sediment concentrations. However, it is suggested that further work should be carried to build on the present study, to determine the long term effects of higher concentrations of suspended sediments on abalone growth. 


\title{
CHAPTER 3
}

\section{The Effect of Suspended Sediment on Oxygen Consumption in the Black Foot Abalone, Haliotis iris}

\begin{abstract}
The present study explores the potential effects of suspended sediments on the oxygen consumption of $H$. iris using concentrations that would typically be found in Wellington Harbour, after heavy rainfall. Laboratory experiments showed with the addition of suspended sediments, this had no effect on the oxygen consumption of H. iris. However there were trends in the data that suggest that smaller sized $H$.iris were affected by the addition of suspended sediment. H. iris may not be vulnerable to suspended sediment within the Wellington Harbour, but could potentially be vulnerable in regions with higher sedimentation rates. $H$. iris is in the top 10 seafood exports in New Zealand, and is a highly valued commercial, recreational and customary fishery. The potential effect of sediment $H$. iris populations could be less resistant to fishing pressure.
\end{abstract}

Key words: Respiration, Abalone, suspended sediment, New Zealand, Haliotis iris.

\subsection{Introduction}

Temperate rocky shores are the most widespread littoral habitat on eroding waveexposed coasts, and comprise of major habitats on sheltered coastlines (Burkett 2013). These shore types contain a high diversity of organisms, but these areas are also subjected to a variety of natural and anthropogenic stressors (Crowe et al. 2000). Environmental stressors include droughts, floods, severe storms and heatwaves. Anthropogenic stressors such as pollution, organic enrichment, physical habitat alterations, and sedimentation (Naranjo et al. 1996), all play a major role in determining the distribution of organisms and local species diversity (Scrosati et al. 2011). 
Temperate rocky shores provide suitable habitat for important and highly valued commercial, recreational and customary fisheries in New Zealand, including abalone (Cook \& Roy Gordon 2010). However, abalone fisheries are suffering worldwide, with major abalone fisheries in the United States and South Africa either having been shutdown, or under threat of closure (Gordon \& Cook 2004). Drastic declines in world abalone stocks over the past three decades have been due to poor government management, overfishing, disease and habitat loss (Cook \& Roy Gordon 2010).

Inputs of sediment into the marine environment derive from natural and anthropogenic processes occuring in both terrestrial and marine environments (Todd et al. 2010). Natural processes include erosion and sedimentation (Burkett 2013). In the marine environment, anthropogenic processes include; dredging and dumping of dredge spoil (Hauraki Maori Trust Board 1999) on land. Inappropriate land management practices can result in run-off and subsequent sedimentation, which can affect the health of shellfish (Hauraki Maori Trust Board 1999). Further, climate change is predicted to increase the frequency and intensity of storms (Burkett 2013).

In New Zealand, due to a combination of geology, active tectonic plates, strong storm events and, associated rainfall as well as large-scale clearances of forests through the development of land-based industries, such as grazing livestocks, farming and exotic forestry. Sedimentation is the most significant land-based stressor on the coastal marine environment (Carter 1975). Sedimentation includes both suspended and deposited loads (Morrison et al. 2009).

The impacts of sedimentation on marine organisms include; clogging of the gills of filter feeders (e.g. cockles, pipi, scallops) (Newcombe \& Jensen 1996), reductions in settlement success (Babcock \& Davies 1991), reduction in visual foraging efficiencies for salmon (Bash et al. 2001), and diminished osmoregulatory abilities of fishes ( $\mathrm{Au}$ et al. 2004). Known effects of sedimentation directly relating to abalone are abnormal larval development, and reduced survival and settlement of larval phases (Phillips \& Shima 2006; (Onitsuka et al. 2010), and altered behaviour 
(Chew et al. 2013). Direct effects for abalone are immediate physiological stress and reduced survival of larvae and juveniles (Miner et al. 2006; Morrison et al. 2009) The blackfoot abalone (Haliotis iris), more commonly known as pāua, is endemic to New Zealand. H. iris are long-lived marine gastropods that inhabit intertidal and subtidal rocky reefs (Will et al. 2011; Aguirre \& McNaught 2012). H. iris are important grazers on rocky reefs with their diet consisting of a variety of soft seaweed (Tong et al. 1992). H. iris also comprise a highly valued commercial, recreational and customary fishery in New Zealand (Aguirre \& McNaught 2012).

Even though abalone is highly valued, and sedimentation is a major stressor in their coastal environments, there is little quantitative information on the effects of sedimentation on abalone. Experiments by Phillips and Shima (2006) found dramatic increases in mortality when $H$. iris larvae were exposed to suspended sediments, with those larvae that did survive being unable to metamorphose. Scheid (1982) also suggested that juvenile $H$. iris were generally absent from exposed coastlines due to a lack of adequate inshore rock habitats. McShane and Naylor (1995a) also noted how high energy turbulence caused sedimentation or shifts in sand, which in turn can cause significant post-settlement mortality.

Wang et al. (2007) found that when Haliotis diversicolor were exposed to highest levels of suspended sediment they exhibited significantly reduced activity. Suspended sediment had physiological effects (e.g. motility), and biochemical effects (e.g. reduced enzyme activity) on $H$. diversicolor, this in turn may cause increased stress and mortality due to predation (Wang et al. 2007).

An investigation by Chew et al. (2013) looked at the potential impact of dredge spoil on the nearby $H$. iris fishery. When $H$. iris were exposed to higher sediment levels, they migrated to areas experiencing lower sediment exposure. However, by moving, $H$. iris is become more vulnerable to predation. Sediment also had an effect on the ability of $H$. iris to re-attach to the substratum.

Oxygen is needed for aerobic metabolism (Fry 1971) and oxygen greatly influences growth in abalone (Harris et al. 1999). There is limited information specifically examining how respiration rates affect growth in $H$. iris. When Haliotis lavigata were exposed to dissolved oxygen concentration of $4.9 \mathrm{mg} \mathrm{L}^{-1}$, they ate less, grew 
slower and had higher mortality compared to controls exposed to $8 \mathrm{mg} \mathrm{L}^{-1}$ (Harris et al 1999). Oxygen consumption of Haliotis discus hannai varied diurnally with more oxygen being consumed during the period from dusk to midnight, with diurnal variation in oxygen consumption attributed to nocturnal feeding behaviour (Barkai \& Griffiths 1988). Oxygen consumption rates were also found to increase for H.tuberculata due to stress of higher seawater temperatures $\left(24^{\circ} \mathrm{C}-28^{\circ} \mathrm{C}\right)$ (McBride et al. 2001).

Although there are limited studies on the effects of suspended sediments on abalone, there have been suggestions that suspended sediment loads could possibly lead to metabolic costs for marine invertebrates (Ragg \& Taylor 2006). Under extreme hypoxia ( $60 \%$ saturation), abalone oxygen consumption rates have been correlated with histopathological changes (Ragg \& Taylor 2006), including necrosis and changes in mucus cell structure in the gills of juvenile Haliotis laevigata (Harris et al. 1998). Fine suspended particles are likely to affect the activity, feeding and respiration rate of gastropods as hypothesised by Cheung et al. (2008).

Management and conservation of $H$. iris populations requires an understanding of the biology, population dynamics and thresholds to environmental conditons (Sainsbury 1982). Knowledge on the effects of suspended sediments on H. iris populations will help provide further information, that may be useful in managing the fishery, and mitigating land-based effects on the coastal marine area. At present, there is limited information on the effects of sedimentation on the oxygen consumption of $H$. iris. Therefore, the primary aim of this study is to determine whether suspended sediment affects respiration rates in juvenile $H$. iris.

\subsection{Materials and Methods}

\section{Sample collection and holding}

Experiments were conducted at VUCEL (Victoria University Coastal Ecology Laboratory) between May $1^{\text {st }}$ and August $25^{\text {th }}$ 2013. Juvenile $H$. iris were sourced from the National Institute of Water and Atmospheric Research aquaculture facility 
at Mahanga Bay, Wellington, New Zealand. Juvenile H. iris had also been tagged prior to collection with plastic shellfish tags. Prior to the experiment, $H$. iris were kept in holding tanks containing free-flowing filtered seawater and conditioned to the local seawater temperatures. H. iris were fed artificial feed AbMax (E.N. Hutchinsons 1td, Auckland, NZ) to excess every 2-3 days. Excess food and faecal matter were cleaned out of the holding tanks every 2-3 days immediately prior to feeding.

\section{Sediment collection and composition}

Sediment used in the experiment was collected from Lake Ferry on $16^{\text {th }}$ August 2011. Grain size analysis was carried out using a laser particle sizer by the School of Geography and Environment and Earth Sciences at Victoria University of Wellington. Analysis of the heavy metal content of the sediment was carried out by Environmental Laboratory Services in Seaview, Lower Hutt.

All suspended sediment loads in the experiment were based on ambient suspended sediment levels estimated for Wellington Harbour after heavy rainfall by Phillips and Shima (2006). The experimental treatments were Control (with H. iris and no added sediment in $100 \mu \mathrm{m}$ filtered seawater, $n=30), 2 \mathrm{X}$ ambient $(H$. iris, with moderate sediment loads i.e., $0.0735 \mathrm{~g} \mathrm{~L}^{-1}$ in $100 \mu \mathrm{m}$ filtered seawater, $n=30$ ) and $4 \mathrm{X}$ ambient (H. iris with high sediment loads i.e., $0.1471 \mathrm{~g} \mathrm{~L}^{-1}$ in $100 \mu \mathrm{m}$ filtered seawater, $n=30)$.

\section{Experimental process}

For each individual $H$. iris used in the experiment, tag numbers were recorded to identify individuals. Measurements of shell length, shell width, and shell height were made in millimetres using steel Vernier callipers and recorded to the nearest two decimal points.

Sediment was placed within a $420 \mathrm{~mL}$ cylindrical Perspex respirometry chamber (Fig. 3.1). The inside of the chamber was lined with black plastic composite tubing so that light was unable to penetrate, since exposure to light may affect the oxygen 
consumption of $H$. iris. An individual $H$. iris was then placed on a perforated shelf and within the chamber, and $100 \%$ oxygen saturated filtered seawater added to the chamber from a reservoir containing filtered seawater aerated with two aquarium bubblers to maintain the dissolved oxygen concentration at $100 \%$ saturation. A magnetic stirring bar was also located inside the chamber underneath the perforated shelf to enable sediment to be suspended. The lid of the chamber was coated in Vaseline and the chamber tightly sealed to prevent additional oxygen entering the chamber. The experiment was conducted in a temperature control room held at a constant temperature of $15^{\circ} \mathrm{C}$ The water temperature in the respirometry chamber was kept constant at $11.4\left(+/-0.35^{\circ} \mathrm{C}\right)$ by placing the chamber in a water bath containing water cooled with a Hailea 150A chiller (Fig. 3.2).

Once the respirometry chamber had its lid sealed, a hand-held YSI-meter (YSI 550A Dissolved Oxygen Instrument probe) was placed inside the chamber via an opening in the chamber lid, to measure dissolved oxygen levels (Fig.3.1). As with the lid, the external casing of the oxygen probe where it contacted with the lid opening was coated with Vaseline to ensure a tight seal. The YSI meter was calibrated at the start of each day experiments to ensure readings were accurate. Dissolved oxygen levels were then measured in both $\mathrm{mg} \mathrm{L}^{-1}$ and $\%$ saturation, with temperature measured in degrees Celsius. All measurements were recorded every minute for 15 minutes, and then every 5 minutes until oxygen saturation dropped to $70 \%$ (see Steger \& Gardner 2007). At the end of the experiment, H. iris were placed back in the holding tanks until the end of the day, and then frozen in a freezer. 


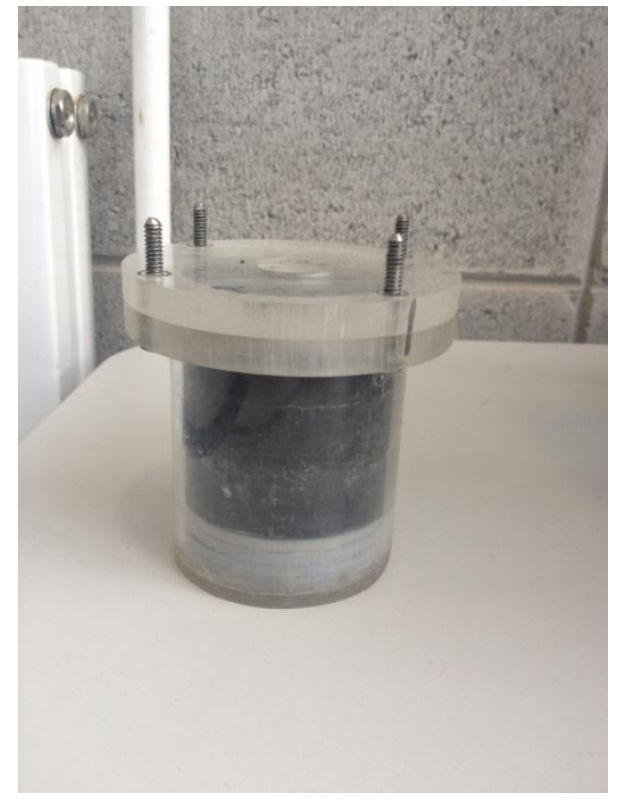

Figure 3.1 Respirometry Chamber, containing black tubing to keep H. iris in total darkness.

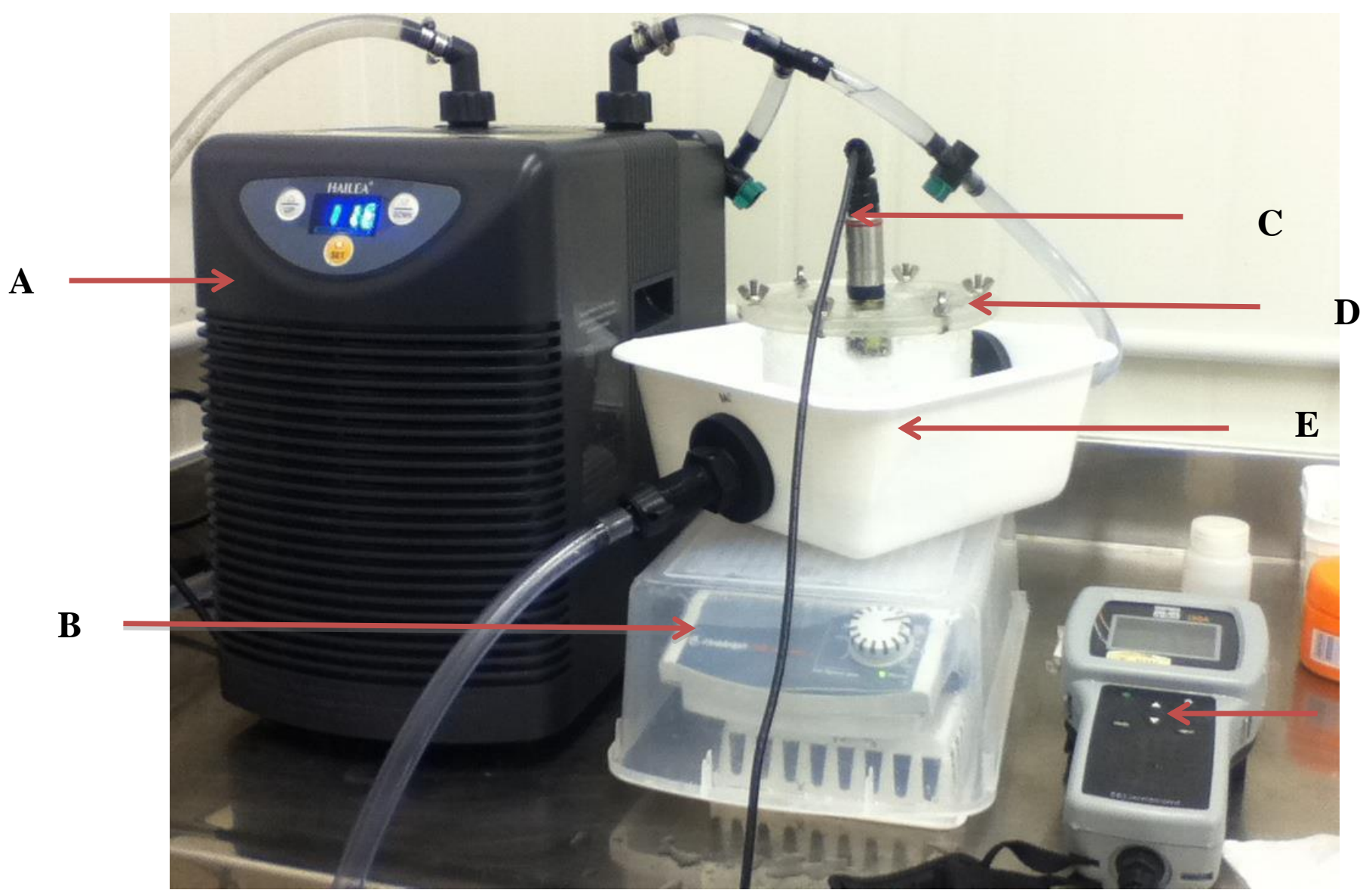

Figure 3.2 Experimental set-up: including (A) Chiller, (B) Magnetic stirrer, (C)YSI-probe, (D) Respirometry chamber (note the chamber is shown without its black lining to show the positioning of the YSI probe) (E) water bath, and (F) YSI-meter. 


\section{Calculation of oxygen consumption}

Oxygen consumption $\left(\mathrm{VO}_{2}\right)$ was calculated using Equation 1. This measured the rate of oxygen consumed in $\mathrm{mg} \mathrm{L}^{-1}$ per hour for each individual pāua.

\section{Equation 3.1.}

$$
\left(\frac{B_{0}-B_{1}}{T}\right) \times 60
$$

Where $B_{0}$ is initial oxygen concentration in $\mathrm{mgL}^{-1}$ at the start of the experiment, $B_{1}$ is the oxygen concentration in mg. $\mathrm{L}^{-1}$ equivalent to $70 \%$ oxygen saturation, and $\mathrm{T}$ is the time in minutes taken for oxygen levels to fall from $100 \%$ saturation to $70 \%$ saturation. Multiplying by 60 gives an hourly oxygen consumption rate.

\section{Size standardisation of oxygen consumption}

After freezing for 24 hours, individual $H$. iris were defrosted, removed from their shells, and placed in foil trays with their tag number for identification. H. iris were then placed in a drying oven at $60^{\circ} \mathrm{C}$ for 24 hours, and then weighed in grams to 4 d.p. using Metler scales to give dry body weight per individual (see Steger \& Gardner 2007). $\mathrm{VO}_{2}$ was then standardised per gram dry body weight by simply dividing $\mathrm{VO}_{2}$ by dry weight $(\mathrm{g})$, with weight standardised $\mathrm{VO}_{2}$ given as $\mathrm{VO}_{2}$.

\section{Statistical analysis}

Temperature and $\mathrm{VO}_{2 \mathrm{~S}}$ for each treatment were plotted. As the temperature data met the assumptions of ANOVA (normally distributed and variance homogeneity). ANOVA was used to test whether temperature was statistically different between treatments. $\mathrm{VO}_{2}$ was also plotted as a function of dry weight for each treatment and relationships examined using simple regression analysis. All of the above analyses were carried out using SPSS version 19 (2011). Examination of the oxygen consumption data showed that while it met the assumptions of variance heterogeneity for ANOVA, the data were not normally distributed. Although ANOVA is robust to data violating the assumption 
of normality, permutational multivariate analysis of variance using the add-on package PERMANOVA+ for the PRIMER software package V6.1 (Cheung et al. 2008)(PERMANOVA) located in the PRIMER software package V6.1 (Steger \& Gardner 2007) was used to test whether there were differences in oxygen consumption rates of $H$. iris between treatments, with oxygen consumption the dependent variable and dry weight a covariate. PERMANOVA makes no assumptions about the underlying distribution of the data. A minimum of 999 permutations of the residuals was done using a Euclidean distance resemblance matrix.

\subsection{Results}

\section{Sediment grain size and heavy metal analysis}

Table 3.1 Results of heavy metal analysis carried out by Environmental Laboratory Services

\begin{tabular}{|l|l|l|l|}
\hline Test & Detection limit & Results & Units \\
\hline Arsenic-Total & $0.05 \mathrm{mgKkg}$ & 4.30 & $\mathrm{Mg} / \mathrm{Kg}$ \\
\hline Cadmium-Total & $0.01 \mathrm{mg} / \mathrm{Kg}$ & 0.01 & $\mathrm{Mg} / \mathrm{Kg}$ \\
\hline Chromium-Total & $0.2 \mathrm{mg} / \mathrm{Kg}$ & 26.2 & $\mathrm{Mg} / \mathrm{Kg}$ \\
\hline Copper-Total & $0.3 \mathrm{mg} / \mathrm{Kg}$ & 8.8 & $\mathrm{Mg} / \mathrm{Kg}$ \\
\hline Lead-Total & $0.1 \mathrm{mg} / \mathrm{Kg}$ & 10.1 & $\mathrm{Mg} / \mathrm{Kg}$ \\
\hline Nickel-Total & $0.2 \mathrm{mg} / \mathrm{Kg}$ & 19.7 & $\mathrm{Mg} / \mathrm{Kg}$ \\
\hline Zinc-Total & $1 \mathrm{mg} / \mathrm{Kg}$ & 57 & $\mathrm{Mg} / \mathrm{Kg}$ \\
\hline
\end{tabular}

All results analysed by ICPMS or ICPOES are reported in dry weight basis

Heavy metal analysis results showed that heavy metal concentrations were well below the Australian and New Zealand Environment Conservation Council Sediment Quality Guideline (2000) trigger values and the Auckland Regional 
Council Environmental Response Criteria (2004) thresholds (See Stephenson et al2008) for further data.

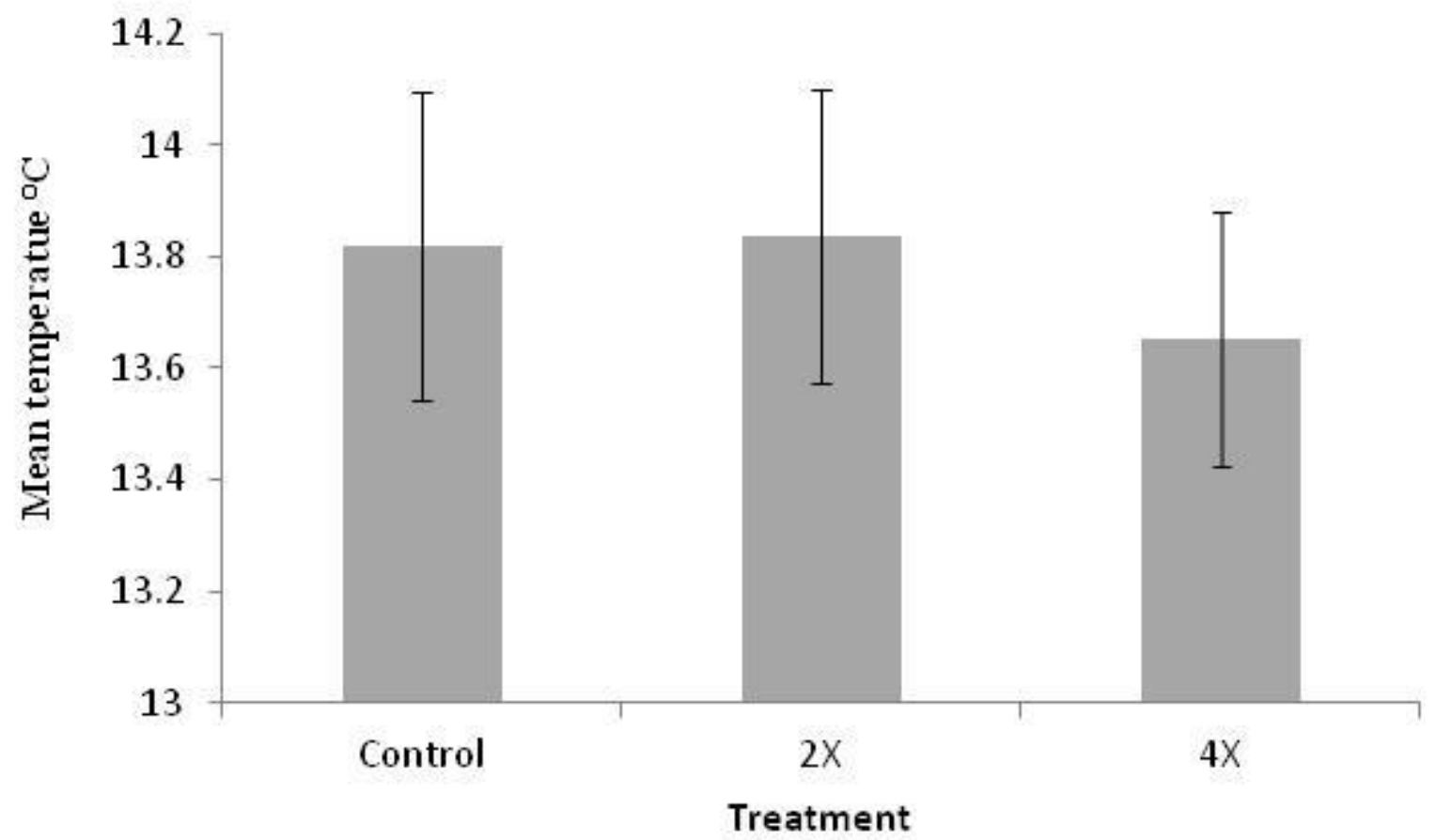

Figure 3.3 Average water bath temperature $\left({ }^{\circ} \mathrm{C}\right)$ for each treatment (Control, $2 \mathrm{X}$ and $4 \mathrm{X}$ ). Error bars are $95 \%$ confidence intervals. 


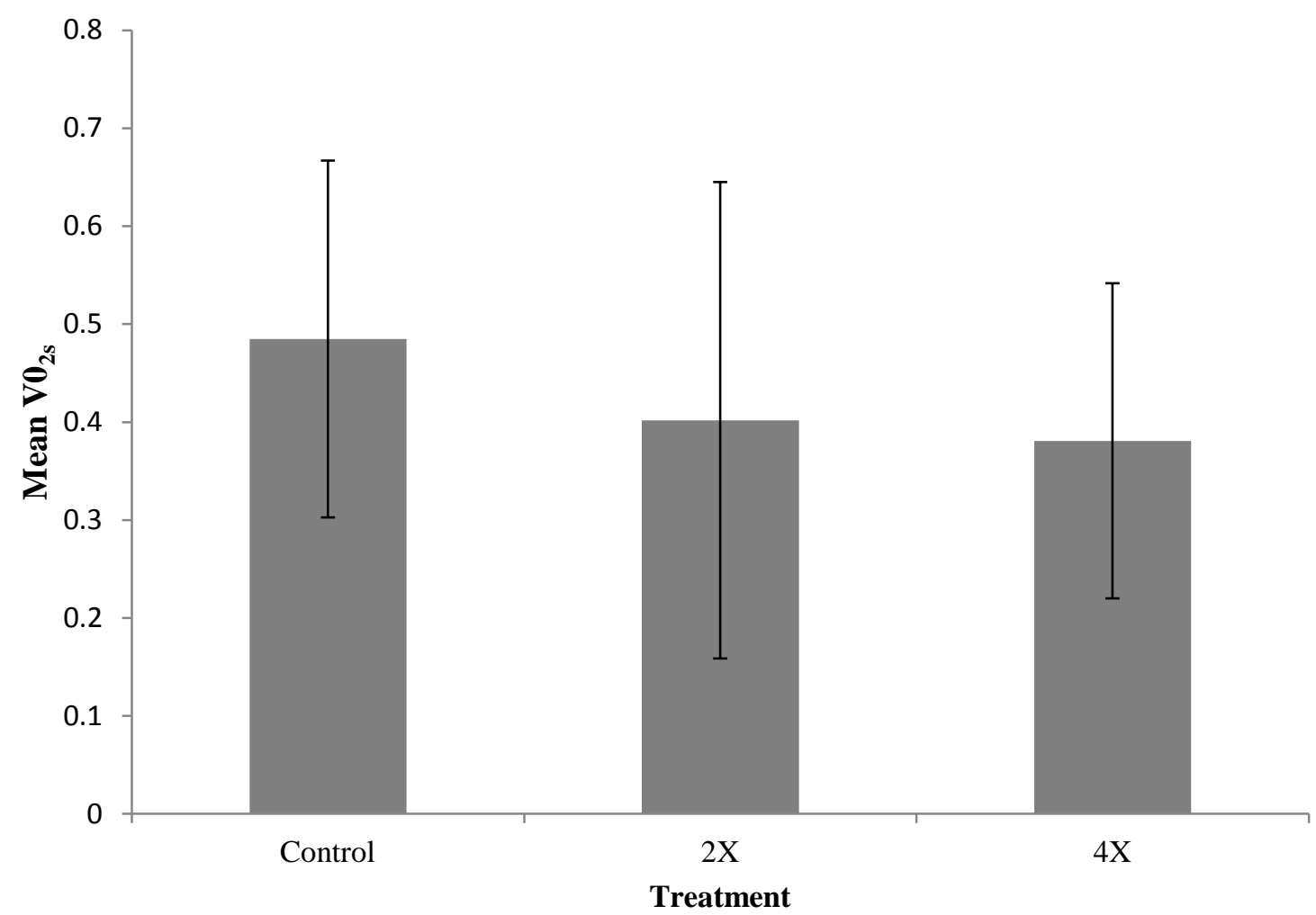

Figure 3.4 Average VO2s (standardised for dry weight) consumption of H.iris across treatments (Control, 2X, and 4X), with (+/- 95\% confidence intervals).

Temperature was not significantly different between treatments, (one-way ANOVA $\left.F_{2,27}=0.76, p=0.555\right)($ Fig.3.3)

There was a non-significant trend of $\mathrm{V}_{2 \mathrm{~s}}$ being highest in the control treatment, and lowest within the $4 \mathrm{X}$ treatment (Fig.3.4). 


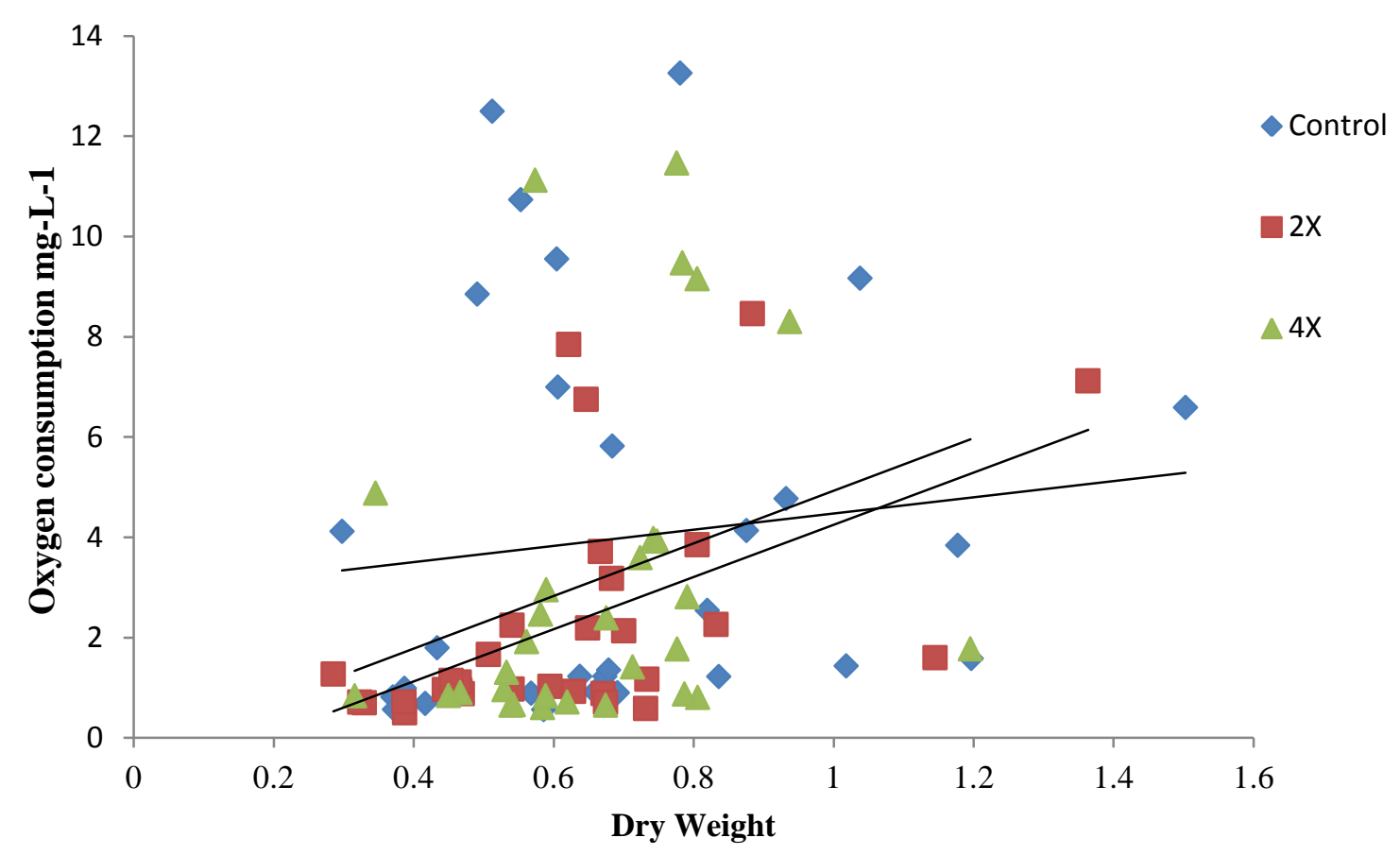

Figure 3.5 Linear relationship between VO2 (mgL-1) as a function of dry body weight $(\mathrm{g})$, for each treatment (Control, $2 \mathrm{X}$ and $4 \mathrm{X}$ ).

Linear regression analysis showed there was no significant relationship between dry weight and treatment, for treatments control ( $\mathrm{VO}_{2}=0.386-0.134$ (dry weight) $F_{1,28}$ $\left.=0.452, p=0.507, r^{2}=0.016\right), 2 \mathrm{X}\left(\mathrm{V}_{2}=0.090+0.228\right.$ (dry weight) $F_{1,28}=0.886, p=0.355$, $\left.\left.r^{2}=0.031\right)\right)$ and $4 \mathrm{X}\left(\mathrm{V} 0_{2}=0.009+0.367\right.$ (dry weight) $\left.F_{1,28}=1.1417, p=0.244, r^{2}=0.048\right)$. However, for all treatments, there was a non-significant trend of increased oxygen consumption with increased dry weight (Fig. 3.5) Analysis using PERMANOVA showed no statistical difference between the oxygen consumption of $H$.iris across treatments $\left(F_{2,27}=0.373, p=0.8103\right)$. However, there was a significant interaction between dry weight and treatment $\left(F_{2,27}=2.722, p=0.043\right)$. At smaller sizes of $H$. iris, oxygen consumption was reduced in treatments $2 \mathrm{X}$ and $4 \mathrm{X}$ in comparison to the control treatment (Fig. 3.5). 


\subsection{Discussion}

This chapter investigated the effect of suspended sediment on the oxygen consumption of $H$. iris. However there was no evidence to suggest that suspended sediment has an effect of oxygen consumption.

Although there was no effect of suspended sediment on the oxygen consumption of $H$. iris, there is evidence to suggest that scallops are highly sensitive to sediment. Work by Stevens (1987) found that pumping rate of scallops (Pecten novaezelandiae) was at silt concentrations of $80 \mathrm{mg} \mathrm{L}^{-1}$ by $92 \%$. Windom and Stickney (1976) suggested that this reduction in oxygen consumption was due to silt film covering the gills and making it harder to respire. Experimental trials on juvenile snapper (Pagrus auratus) examined the effect of feeding rates of live prey with the addition of sediment. With prolonged exposure to sediment, snapper were negatively affected with increased coughing and gulping, higher respiration rate and decreased activity. Sub-lethal effects included gill deformities (Morrison et al. 2009). Although in the present study there was no evidence to suggest that oxygen consumption in H.iris was affected by suspended sediment. Work by Stevens (1987) and Morrison (et al.2009) used much higher concentrations of sediment in comparison to the present study.

PERMANOVA results showed although there was no significant effect of treatment, there was a significant interaction between dry weight and treatment. These results indicate smaller sized $H$. iris might be more vulnerable to sediments so their oxygen consumption is reduced. According to (Foster 1971; Gosselin \& Qian 1997; Moran 1999) juvenile survivorship is thought to improve with age and size, becoming less vulnerable to desiccation, predation and other factors. In the present study larger $H$. iris could have been less vulnerable to the effects of suspended sediment independent of suspended sediment concentration.

There was no statistically significant effect of suspended sediment on the oxygen consumption of $H$. iris. However there was a trend of reduced oxygen consumption with increased suspended sediment levels. Treatments exposed to suspended sediment had lower rates of oxygen consumption. This could support Ragg \& Taylors (2006) that suspended solids have the potential to block water channels of the gill lamellae, this 
would then acquire being a metabolic cost to $\mathrm{H}$. iris, due to increased production of mucus to clear gills. Thus effective oxygen consumption could be reduced.

The present study was undertaken within the laboratory under controlled conditions, and did find that oxygen consumption is affected by suspended sediment. However in the wild $H$. iris are exposed to various other factors for example in Preece and Mladenov (1999) study found, worm infestations and encrusting organisms such as barnacles, sponges and tubeworms that covered the respiratory pores and inhibited water flow through the mantle. Their study was interesting and found that dead H. iris shells had nacre-covered silt capsules indicating they were in close proximity to nearby land run-off. In combination with encrusting organisms covering respirations pores and exposure to silt this may have lethal effects including suffocation, and could eventually cause mortality within $H$. iris populations.

Robinson et al. (2012), indicated that movement is a measurement of stress, although he also noted that stress is also difficult to measure. Identifiable measures of stress are limited within the literature and in the present study stress could be potentially measured by the rate of oxygen consumed. Stress responses towards the addition of suspended sediment could possibly be an increase in oxygen consumption rate or decrease in oxygen consumption rate. In the present study there was a trend that oxygen consumption rate decreased when exposed to suspended sediment. This could potentially be a stress response by shutting down important functions in fear of damage to organs.

Regression results indicated that there was not a strong relationship between oxygen consumption and dry weight for each treatment indicating high variability within $H$. iris tested in the present study. This was also evident in experiments by Taylor and Ragg (2005) who found that ventilation in $H$. iris was highly variable in individuals due to a number of different behaviours each H. iris displayed. Hooker et al. (1997) also found that growth of $H$. iris was highly variable when shell length was below $25 \mathrm{~mm}$.

With increased sediment concentrations there maybe potential negative effects on $H$. iris, as studies on other marine organisms have found lethal effects i.e. Reduction in pumping rate of scallops, higher respiration rate and gill deformities in snapper. Environmental managers however should be cautious, as the present study only concentrated on sediment levels within the Wellington Harbour; which in comparison to 
other regions in New Zealand are low. H. iris may not be vulnerable to suspended sediment within the Wellington Harbour, but could be potentially be vulnerable in regions with high sedimentation rates.

Improvements to this study would be to use wild $H$. iris, as although there was no affect suspended sediment on cultured stock, there may be an affect to wild populations. Cultured stock however could be more resistant to sediment due to ongoing handling, and built up resistance. Another way to improve this study would be to use concentrations typically found in South Westland and East Cape which are 15 times higher than concentrations used in this study. H. iris is in the top 10 export New Zealand export species and is a highly valued commercial, recreational and customary fishery. The potential effect of sediment on $H$. iris populations make them less resistant to fishing pressure.

\subsection{Conclusion}

The present study presents interesting results, where with the addition of suspended sediments $H$. iris oxygen consumption was unaffected. However there were trends in the data to suggest that smaller $H$.iris are sensitive to suspended sediments. Others have found that oxygen consumption can either be reduced or increased in other shell fish species. Suspended sediment in the water column could induce a stress response where $H$. iris reduces the amount of oxygen consumed. In spite of this studies have shown that $H$. iris are highly variable, and there are fundamental gaps in our knowledge on how $H$. iris is affected by suspended sediments which could be further explored. 


\title{
CHAPTER 4
}

\section{The Effect of Suspended Sediments on the Mucus Production in the Black Foot}

\author{
Abalone, Haliotis iris.
}

\begin{abstract}
With increased anthropogenic activities such as logging, farming of livestock, road building, agriculture and forestry, sedimentation has become the most important landbased stressor in New Zealand. The present study tests the effects of suspended sediment on the mucus production of $H$. iris, in relation to suspended sediment concentration, that would typically be found in Wellington Harbour after heavy rainfall. The results show there was a significant difference in mucus production between treatments. Those that were exposed to suspended sediment did not produce mucus; however those that were in the control treatment did produce mucus. These results were indicate suspended sediment could possibly initiate a stress response where $H$.iris suppress water intake, limiting water to produce mucus.
\end{abstract}

Key words: H.iris, suspended sediment, mucus

\subsection{Introduction}

Anthropogenic activities are increasing the intensity of stressors, that impact many coastal zones worldwide (Halpern et al. 2008). One of these stressors that is enhanced by anthropogenic activities is sedimentation. Sedimentation is an important threat to biodiversity in most aquatic ecosystems (Gray 1997). In recent times, human activities have led to large increases in the amount of sediment going into the marine environment; particularly from land masses bordering the Pacific Rim (Lohrer et al. 2006). Activities such as logging, farming of livestock, and road building, have been some of the most important stressors within near shore habitats (Lohrer et al. 2006). Manipulative and observational studies on rocky shore assemblages, have shown 
dramatic changes in the structure of invertebrate assemblages in response to increased sediment loads, resulting in either positive (increased recruitment of algae) (Kennelly 1987), or negative impacts (inhibition of grazing) (Umar et al. 1998), smothering and suffocation by clogging of respiratory pores or indifferent responses by species (i.e. domination of opportunistic seaweeds) (Airoldi 1998).

Much invertebrate physiological activity involves mucus including, predator deterrence (Simkiss \& Wilbur 1977), and filtration of the haemolymph (Davies \& Hawkins 1998). Mucus can also help clean particles from the mantle cavity (Crofts 1937). For movement in abalone, mucus is secreted from glands of foot, which forms a sheet of mucus on the substratum, which they can slide on (Donovan \& Carefoot 1998). This form of movement is referred to as adhesive crawling, and can be energetically expensive compared to other forms of locomotion (Denny 1984). Mucus can also function as a sensory cue (Davies \& Hawkins 1998), with abalone larvae depending on the recognition of external chemical signals in the water column for settlement, including biotic films or mucus produced from grazing adults, to signal metamorphosis (Seki \& Kan-No 1981; Tung \& Alfaro 2011).

Mucus production can be energetically costly, comprising up to $70 \%$ of an animal's consumed energy (Davies \& Hawkins 1998), so it is important to account for mucus in the assessment of energy budgets, especially for gastropods, because a significant amount of energy is allocated to mucus production for locomotion (Peck et al. 1987). In Haliotis tuberculata $23 \%$ - $29 \%$ of the total energy budget was allocated to mucus production (Davies \& Hawkins 1998), which is much higher than the $4 \%$ previously estimated (Peck et al. 1987).

In Haliotis iris production of mucus is believed to have various roles including; removal of waste from mantle cavity (Simkiss \& Wilbur 1977), adhesion to the substrate (Smith 1991), acting as a predator deterrent and filtration of the haemolymph (Ragg 2003). Importantly, mucus production at high concentrations of fine suspended solids has been postulated by Ragg (2003) to have significant metabolic costs, possibly causing blockage of the gill lamellae and loss of adhesion to the substrata. H. iris produces vast amounts of mucus when stressed, in particular when they are being handled. Handling 
can be harmful because they lose their foot- hold after re-immersion (Simkiss \& Wilbur 1977). Mucus also attracts predators such as cod, and without strong foot-holds it makes them vulnerable to predation. Righting response is an important behaviour in abalone. Timing of this behaviour is important since individuals can be dislodged during strong wave action by predators, and the abalone must recover their position to avoid being washed away or eaten (Minchin 1975). Chew et al. (2013), found that H. iris was unable to right themselves when the substrate was covered with $1 \mathrm{~mm}$ thick silt.

Only one study by Wang et al. (2007) has investigated the physiological responses of Haliotis species when exposed to suspended sediment stress. Their results showed that there was no mortality within 96 hours of exposure, to moderately high amounts of suspended sediment, but motility was significantly weakened. However, the authors didn't investigate mucus production in response to suspended sediment loads.

Considering the high energetic cost associated with the production of mucus, and the lack of knowledge on the effects of suspended sediment on Haliotis iris, the aim of this experiment is to test whether suspended sediment affects mucus production in juvenile H. iris.

\subsection{Methods}

\section{H. iris collection and holding}

Juvenile $H$. iris used in this experiment were obtained from the National Institute of Water and Atmosphere Research (NIWA) at Mahanga Bay, Wellington, New Zealand. H. iris (20 - 40mm shell length) were kept in holding tanks with free flowing filtered seawater and conditioned to local seawater temperatures. They were fed artificial feed AbMax (E.N. Hutchinsons 1td, Auckland, and NZ every 2-3 days, with tanks cleaned prior to feeding.

\section{Tagging and measuring $\mathrm{H}$. iris}

$H$. iris were tagged one week- prior to the experiment using numbered plastic tags and super glue (Holdfast Gorilla Super Glue Ultra-Bonder Power Liquid - Product no: 41344) Measurements of shell length (the longest point of the shell) was done to the 
nearest $0.01 \mathrm{~mm}$ were made prior to the experiment for all individuals using steel vernier callipers.

\section{Sediment analysis and concentration}

Suspended sediment concentrations used in the experiment were based on those used by Phillips and Shima (2006), which were based on concentrations found after heavy rainfall in Wellington Harbour. The experimental treatments were Control (with H. iris and no added sediment in $100 \mu \mathrm{m}$ filtered seawater, $n=10), 2 \mathrm{X}$ ambient $(H$. iris, with moderate sediment loads i.e., $0.0735 \mathrm{~g} \mathrm{~L}^{-1}$ in $100 \mu \mathrm{m}$ filtered seawater, $n=10$ ) and $4 \mathrm{X}$ ambient (H. iris with high sediment loads i.e., $0.1471 \mathrm{~g} \mathrm{~L}^{-1}$ in $100 \mu \mathrm{m}$ filtered seawater, $n=10)$. Sediment used in the experiment was collected from Lake Ferry on $16^{\text {th }}$ August 2011. Grain size analysis was carried out using a laser particle sizer by the School of Geography and Environment and Earth Sciences at Victoria University of Wellington. Analysis of the heavy metal content of the sediment was carried out by Environmental Laboratory Services in Seaview, Lower Hutt.

\section{Experimental design and process}

H. iris were cleaned of any faecal matter and amphipods that may have been in the holding tanks using a wash bottle containing filtered seawater. Each $H$. iris was then placed in its own $565 \mathrm{ml}$ cylindrical plastic container (Tekpac Industries T303 - Tub, 565/110 MTE) containing $400 \mathrm{ml}$ of flow-through filtered sea water i.e., one animal per container. H. iris were acclimated in these experimental containers to salinity and water temperature conditions similar to those in the field for 72 hours prior to the experiment and were not fed during this time (or at any time during the experiment). This was to ensure no faecal matter was produced by $H$. iris during the experiment. $H$. iris were also kept in complete darkness (Todd \& Dehnel 1960).

\section{Sediment treatments}

Immediately prior to staring the experiment, the flow-through seawater was turned off. H. iris were left in their replicate containers but the seawater was removed and replaced with seawater filtered through a $0.2 \mu \mathrm{m}$ filter to ensure it was free of sediments. Experimental treatments comprised Control (no sediment), 2X Ambient (filtered seawater with $0.029 \mathrm{~g} \mathrm{~L}^{-1}$ of sediment added), and $4 \mathrm{X}$ Ambient (filtered seawater with 
$0.058 \mathrm{~g} \mathrm{~L}^{-1}$ of sediment added). Each treatment had 10 replicate containers holding a single $H$. iris, giving, in total, 30 juvenile $H$. iris. The sediment for each replicate in the 2X and $4 \mathrm{X}$ sediment treatments was weighed using Metler scales to the nearest three decimal points and added to the appropriate replicate containers. As the seawater was no-longer flow-through, perspex paddles were placed into each container. The paddles were suspended from a wooden rack that moved backwards and forwards every second. Silicone tubing with small holes in it was also glued to the paddles. The silicon tubing was connected to an air pump that provided a constant air flow, keeping the sediment in the experimental containers suspended at all times, and providing $H$. iris with oxygen. A diagram of the experimental setup is shown in (Fig.2.1.). The experiment was left running for 24 hours.

\section{Mucus production \& Filtering}

After 24 hours, H. iris were removed from the containers and their foot scraped with blunt forceps to remove any mucus that may have been on the foot. This mucus was put back into the experiment container. Each $H$. iris was also then rinsed with distilled water, with the rinsed material washed back into the animal's experimental container.

To estimate mucus production for each individual $H$. iris, mucus was filtered from the water in the experimental containers. Prior to filtering, filter papers (Whatman Glass Fibre Filters $1.2 \mu \mathrm{m}$ ) were weighed using Metler -scales to the nearest 0.001 grams and dry weights recorded for each replicate. The contents of the experimental container were then poured through a conical flask filter. The Filter papers were then placed in a $60^{\circ} \mathrm{C}$ oven for 24 hours to dry, left to cool, and then re-weighed to get dry weight including mucus and sediment. Mucus production was then calculated using equation 4.1 .

$H$. iris were then frozen for 24 hours and then defrosted, removed from their shell, then placed in a $60^{\circ} \mathrm{C}$ oven for 24 hours. They were then weighed using Metler Scales (dry body weight per individual. $4 \mathrm{dp}$ ). The tag number was also noted so that individual $H$. iris could be identified.

\section{Equation 4.1}

$$
M=\left(P_{1}-P_{0}\right)-S
$$


Where $M$ is mucus production in grams, $P_{l}$ is dry weight of the filter paper after filtering and drying (including sediment and any mucus), $P_{0}$ is the dry weight of the filter paper prior to the experiment, and $S$ is the dry weight of the sediment taken prior to its addition to the individual container.

\section{Statistical analysis}

Prior to analysis, data were checked for normality and homogeneity of variance. The data met the assumptions of ANCOVA so data was not transformed. Regression analysis was performed to examine relationships between and dry weight and mucus production. ANCOVA was used to test whether there was an effect of sediment on mucus production, with $H$. iris dry weight as a covariate. All of the above analyses were carried out using (SPSS), version 19 (2011)

\subsection{Results}

Table 4.1 Results of heavy metal analysis carried out by Environmental Laboratory Services.

\begin{tabular}{|l|l|l|l|}
\hline Test & Detection limit & Results & Units \\
\hline Arsenic-Total & $0.05 \mathrm{mgKkg}$ & 4.30 & $\mathrm{Mg} / \mathrm{Kg}$ \\
\hline Cadmium-Total & $0.01 \mathrm{mg} / \mathrm{Kg}$ & 0.01 & $\mathrm{Mg} / \mathrm{Kg}$ \\
\hline Chromium-Total & $0.2 \mathrm{mg} / \mathrm{Kg}$ & 26.2 & $\mathrm{Mg} / \mathrm{Kg}$ \\
\hline Copper-Total & $0.3 \mathrm{mg} / \mathrm{Kg}$ & 8.8 & $\mathrm{Mg} / \mathrm{Kg}$ \\
\hline Lead-Total & $0.1 \mathrm{mg} / \mathrm{Kg}$ & 10.1 & $\mathrm{Mg} / \mathrm{Kg}$ \\
\hline Nickel-Total & $0.2 \mathrm{mg} / \mathrm{Kg}$ & 19.7 & $\mathrm{Mg} / \mathrm{Kg}$ \\
\hline Zinc-Total & $1 \mathrm{mg} / \mathrm{Kg}$ & 57 & $\mathrm{Mg} / \mathrm{Kg}$ \\
\hline
\end{tabular}

All results analysed by ICPMS or ICPOES are reported in dry weight basis

Heavy metal analysis results showed that, heavy metal readings were well within the Australian and New Zealand Environment Conservation Council Sediment Quality Guidelines (2000) (see Stephenson et al. (2008) for further detail). Total sediment grain size composition comprised $68.15 \%$ silt, $29.09 \%$ sand and $2.76 \%$ clay. Sediment was analysed for heavy metals by Environmental Laboratory Services (ELS) in Seaview, Lower Hutt 


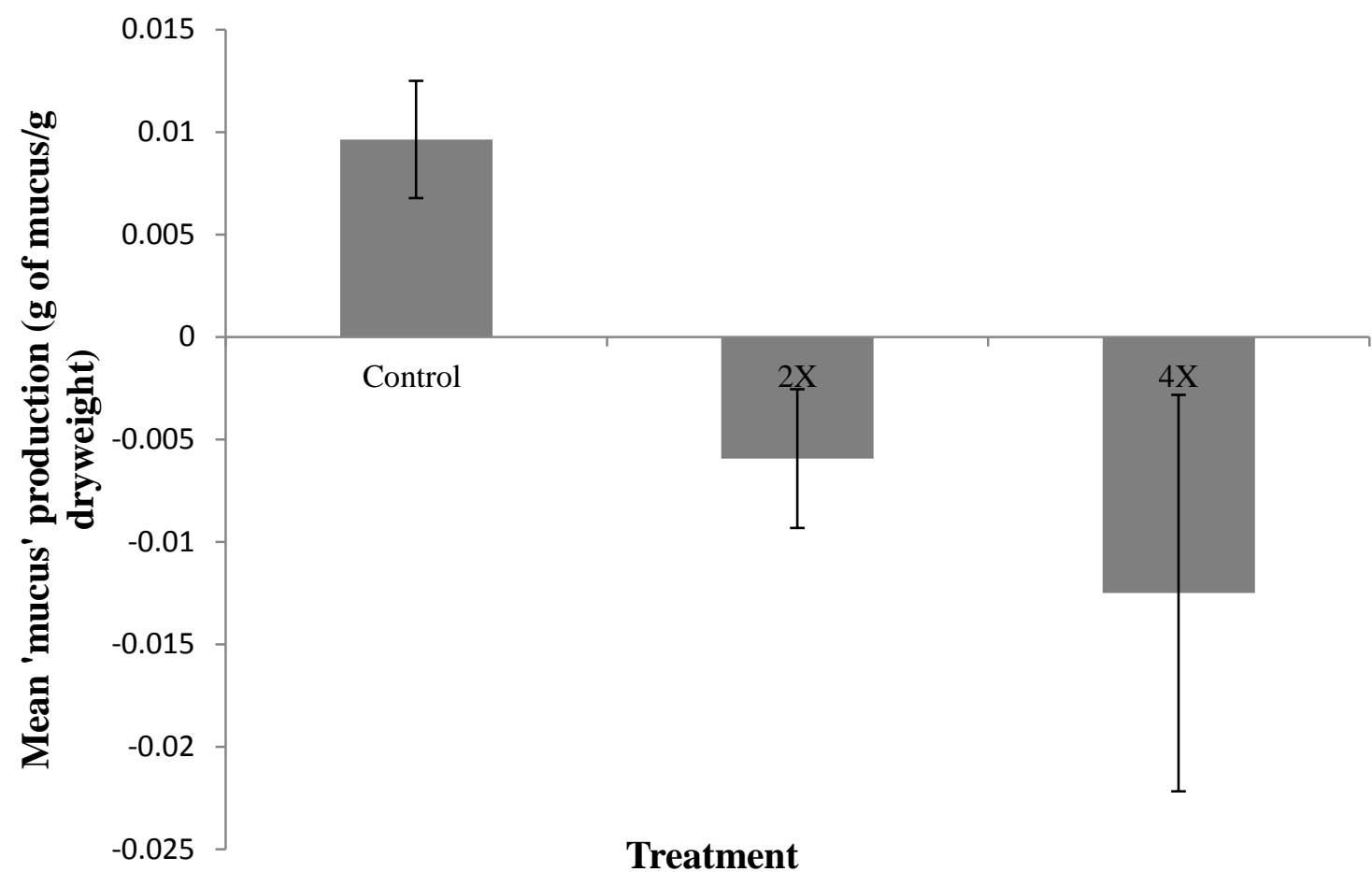

Figure 4.1 Average mucus production (g) (standardised by dry weight) for $\mathrm{H}$. iris for treatments (control, 2X and 4X) Error bars are 95\% confidence intervals.

Average mucus production was highest within the control treatment than the $2 X$ treatment, and $4 \mathrm{X}$ treatment. The $2 \mathrm{X}$ treatment had a loss of roughly $50 \%$ of the mucus produced in the Control, while the $4 \mathrm{X}$ had a loss of slightly more than the mucus produced in the control, although error bars for the $4 \mathrm{X}$ are relatively wide (Fig.4.1). 


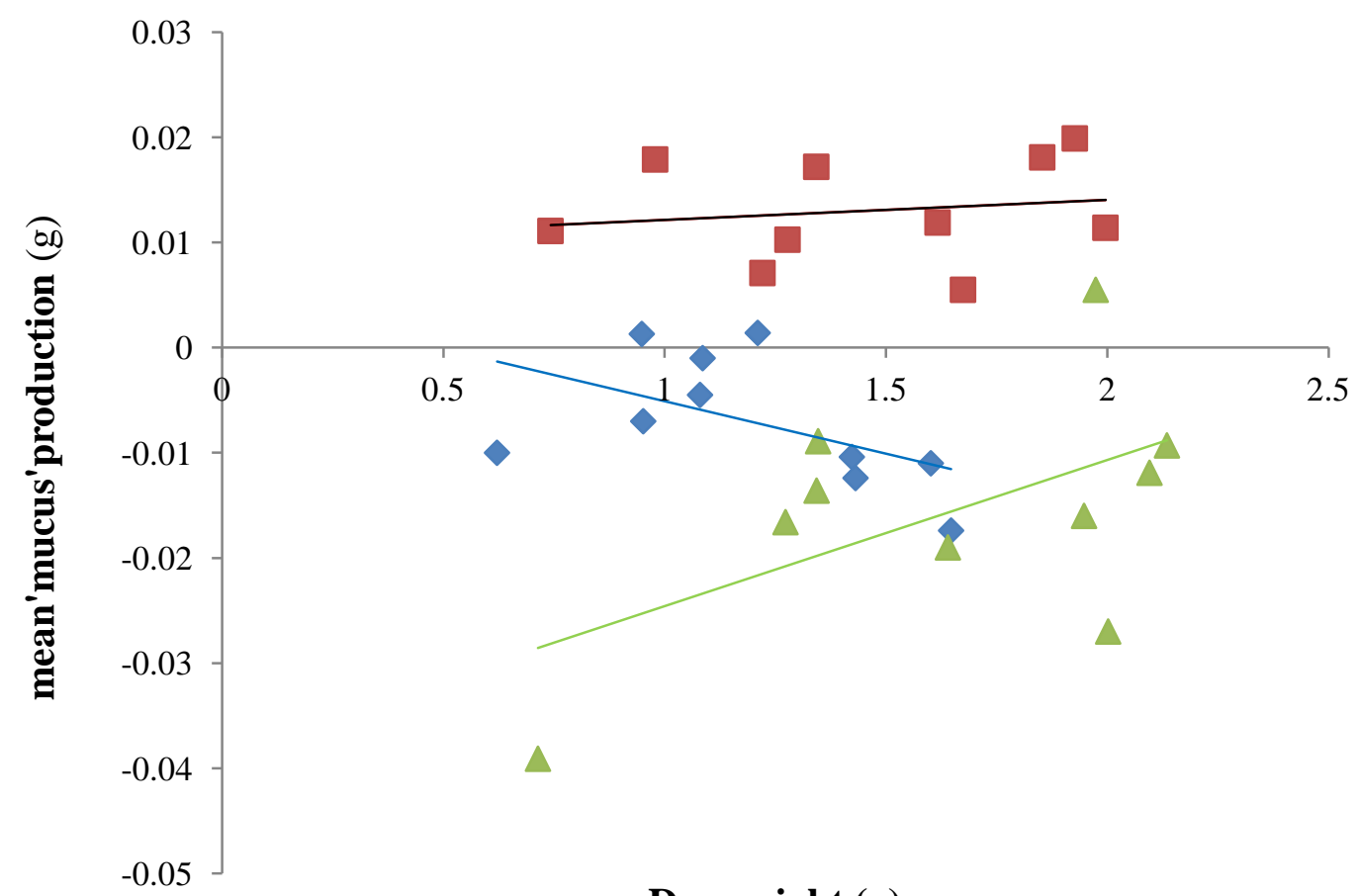

Control

Dry weight (g)

Figure 4.2 Linear regression between Dry weight $(\mathrm{g})$ as a function of mucus production $(\mathrm{g})$, for each treatment (Control, $2 \mathrm{X}$ and $4 \mathrm{X}$ ).

Linear regression between mucus production and dry weight for treatments control (Mucus $=0.010+0.002$ (Dry weight) $F_{1,8}=0.213, p=0.657, r^{2}=0.026$ ), $2 \mathrm{X}$ (Mucus $=0.005$ - 0.10 (Dry weight) $F_{1,8}=2.922, p=0.126, r^{2}=0.268$ ), and $4 \mathrm{X}$ (Mucus $=-0.038+0.014$ (Dry weight) $F_{1,8}=3.493, p=0.099 r^{2}=0.304$ ) (Fig.4.2). Average mucus production of $H$. iris was highest within the control treatment; there was a gradual increase in mucus production as dry weight increased (Fig. 4.2). In the $2 X$ and $4 X$ treatments, there was a loss of weight recorded between the filter paper and sediment at the start of the experiment, and the final weight of the filter paper and filtered material at the end of the experiment, this resulted in negative values (Fig.4.2).

ANCOVA showed that the effect of treatment was significant for mucus production of H. iris $\left(F_{1,24}=8.564, p=0.002\right)$, with a significant interaction between dry weight and mucus production $\left(F_{1,24}=3.413, p=0.049\right)$. 


\subsection{Discussion}

The results of the present study confirm that suspended sediment has an effect on the mucus production of $H$. iris. With the addition of suspended sediment, $H$. iris does not appear to produce mucus.

There is little empirical knowledge in the literature that has looked at the effects of suspended sediment on the mucus production of $H$. iris. This is one of the first experiments to explore the effects of suspended sediment on the mucus production of $H$. iris, but also any abalone species. However there is a growing body of research on the effects of sediment and mucus production of coral.

Corals have a variety of mechanisms that they use to expel unwanted sediment. Mucus is produced to entangle sediment particle and is later expelled (Hubbard \& Pocock 1972). However only a few species are able to tolerate sediment stress e.g. Portites species. Coral survival is dependent not only on coral species but also sediment type between environmental conditions (Fabricius 2005). For the present study, the sediment grain size used was $68 \%$ silt, and only the control treatment produced mucus. Sediment used in the experiment may have been too fine to stimulate a mucus production response and exposure to sediment was only 24 hours. Longer exposure may have resulted in mucus production in sediment treatments.

Sub-lethal effects of sediment to corals are complex. Bak and Elgershuizen (1976) observed $33 \%$ reduction in growth rates and concluded that corals suffered from metabolic shock since zooxanthellae were not expelled from the coral. However Peters and Pilson (1985) did not find there was any effect of sediment on growth, but found the process of sediment removal caused tissue damage, depleting energy reserves through mucus production for removal of sediment.

Simkiss and Wilbur (1977) noted that when abalone clamped down to the substrate they did not produce mucus. This could possibly be a response to stress when exposed to foreign substances in the water column, causing suppression in drinking. Restriction of oral uptake (drinking) is done by retracting the head preventing uptake of foreign 
substances (Simkiss \& Wilbur 1977). This has also been found in teleost fish. Fletcher (1992) who noted that fish tend to suppress drinking when stressed. Ragg (2003) also found that $H$. iris response to stress is to retract their head that restricts oral water uptake. The reaction of $H$. iris to stress by limiting water uptake would reduce fluids to produce mucus. In this experiment $H$. iris that were not exposed to sediment produced normal amounts of mucus, possibly since they were not under stress.

Another theory why there were negative amounts of mucus produced in the present study could reflect results found by Davies and Hawkins (1998) who found with increased stress gastropods produce a thinner more watery mucus, with mucus going back to its former solid state when the stress is released. In the present study mucus may have been produced, but since it may have been in a watery state during filtering this may have been filtered through the filter, accounting for negative amounts of mucus production.

Dry weight - filter paper $=$ mucus production was negative for all treatments that were exposed to suspended sediment. In this instance sediment may have also been engulfed by $H$. iris and still retained in the mantle cavity and this was not accounted for in the final measurement of weight. Theories by Davies and Hawkins (1998) could explain why with sediment still retained within the mantle, mucus produced may have been to watery and may not have been efficient to clear the mantle of sediment. Simkiss and Wilbur (1977) also found that abalone that clamped down, did not produce mucus. Their results could also explain negative mucus production in the present study, since no mucus was produced; sediment was possibly retained within the mantle and was not accounted for in the final measured weight.

Linear regression results show that there was no strong relationship between dry weight and mucus production. Within the Control treatment, there was a trend of increased mucus production as dry weight increased. However for $2 \mathrm{X}$ and $4 \mathrm{X}$ treatments, it is uncertain whether mucus was produced or whether sediment was ingested and retained in the mantle cavity. Improvements to experimental design would be to increase experimental time, exposing $\mathrm{H}$. iris to suspended sediments for prolonged amounts of time. In the present study $H$. iris were only exposed for 24 hours. 
Animals with poorer health tend to produce less mucus and less stickiness which can result in reduced ability to turn themselves over. Tung \& Alfaro (2011) suggested the number of goblet cells and epithelial thickness can indicate mucus production and an indication of abalone health (Tung \& Alfaro 2011). Further research is needed on the effects of suspended sediment on the mucus production of $H$. iris. Future work could be based on the goblet cells and epithelial thickness to be able to test the effect of sediment on mucus production. Also there could possibly be remaining sediment within the mantle cavity of the $H$. iris that were exposed to sediment. Ashing of $H$. iris to see if sediment remained in mantle would confirm theories that sediment was ingested by $H$ .iris, and exposure to sediment may have provoked a 'shutdown' response of essential functions i.e. mucus production.

\subsection{Conclusion}

Evidence in the present study show that suspended sediment has an effect on the mucus production of $H$. iris with exposure to suspended sediments. $H$. iris may initiate a stress response by 'clamping' down to the substrate and limiting water intake, in fear of damage to internal organs. Exposure to suspended sediments for longer durations of time may lead to more energy being allocated to dealing with stress and less towards growth and reproduction. 


\section{CHAPTER 5}

\section{General discussion and Conclusions}

There is limited information on the effect of suspended sediments on gastropods, even though sedimentation is one of the most significant land based stressors in New Zealand, and a major issue worldwide (Devlin \& Brodie 2005). This thesis presents a series of laboratory experiments examining the effect of suspended sediment on growth, oxygen consumption, and mucus production for the abalone, Haliotis iris, using suspended sediment concentrations based on loads that would naturally occur after heavy rainfall in the Wellington Harbour. This chapter briefly summarises the major findings, limitations, and conclusions of this work, suggests further work, and possible management measures to mitigate sediment impacts on the marine environment.

There has been very little work carried out globally to quantify the effects of suspended sediment on $H$. iris populations. Onitsuka et al. (2008) carried out experiments on the effects of sediment on $H$. iris larvae, however the majority of research on the effects of suspended sediment has been concentrated on corals (Hubbard \& Pocock 1972), salmon (Bash et al. 2001) and mussels (Wilber \& Clarke 2001). It has been suggested that sediments have impacts on $H$. iris. This was seen in experiments by McShane (1995) who hypothesized that $H$. iris are generally absent from exposed coastlines due to turbulence of re-suspending sediments. Ragg (2003) suggested that exposure to suspended solids could increase mucus production, incurring a metabolic cost to $H$. iris, but these two hypotheses have not yet been experimentally tested. Phillips and Shima (2006) found increased mortality rates of $H$. Iris larvae when exposed to increased concentrations of suspended sediment, but again, any effects have not yet been tested on juvenile or adult populations. Chew et al. (2013) recently investigated the behaviour of $H$. iris when exposed to sediment and found $H$. iris avoided sediments, resulting in them moving from predation refugia beneath cobbles to more exposed areas where they were vulnerable to predation. The studies by Phillips and Shima (2006) and Chew et al. (2013) are the only ones that have examined the effects of suspended and deposited sediments on H. iris. Consequently, there are large gaps in the knowledge surrounding the effects of suspended sediment on $H$. iris populations, including effects on growth, oxygen consumption rates, and mucus production. 


\section{The effect of suspended sediment on growth}

There was no evidence to suggest growth is affected by suspended sediment. Growth of $H$. iris is highly variable, making it difficult to detect any effect of sediment on growth. However, the size range of $H$. iris used in this study could be resistant to sediment concentrations used. Concentrations in Wellington Harbour are low in comparison to in stitu concentration elsewhere in New Zealand. Stress could have been a factor contributing to the little observed differences in growth. All H. iris in the experiment were potentially under significant stress from handling. As a consequence, they may have allocated more energy towards dealing with the stress of handling, and less towards growth.

\section{Does suspended sediment affect respiration?}

The present study found no effect of suspended sediment on the oxygen consumption of $H$.iris. However, there were trends in the data to suggest that smaller $H$. iris is more sensitive to suspended sediments. Suspended sediment in the water column could induce a stress response where $H$. iris reduces the amount of oxygen consumed. Similar experiments have explored the effect of suspended sediments in other marine organisms, with conflicting results. Work by Stevens (1987) found that pumping rate of scallops was reduced when exposed to silt concentrations. Whereas unpublished data found in Morrison (2009) found increased respiration rates in snapper when exposed to sediment. However, concentrations of sediment used in these experiments were a lot higher than those used in the present study. In spite of these studies this study has shown that $H$. iris is highly variable, and there are fundamental gaps in our knowledge on how $H$. iris is affected by suspended sediments, and could be further explored.

\section{The effect of suspended sediment on mucus production}

Suspended sediments had a significant effect on mucus production in $H$. iris, with no mucus produced when exposed to suspended sediments. Simkiss and Wilbur (1977) observed that abalone that clamped down on the substrate did not produce mucus. This could possibly be a response to stress when exposed to foreign substances in the water column, causing suppression in drinking. Restriction of oral uptake (drinking) is done 
by retracting the head preventing uptake of foreign substances. This has also been found in teleost fish, with Fletcher (1992) noting that fish tend to suppress drinking when stressed. Stress can also result in mucus being more watery. Davies and Hawkins (1998) found gastropods produce a thinner more watery mucus when stressed, and mucus going back to its former solid state when stress is released. In the present study, mucus may have been produced, but since it may have been in a watery state during filtration stage this may have been filtered through the filter, and accounting for negative amounts of mucus production.

\section{Implications}

One of the only studies that have examined the effects of suspended sediment on $H$. iris was by Phillips and Shima (2006), and examined effects on larval life stages. Importantly, the significant lack of knowledge around the impacts of suspended sediments on $H$. iris limits our ability to predict the implications of increasing sediment loads that are making their way into the coastal marine environment. Laboratory experiments showed that $H$. iris was tolerant to sediment concentrations and growth and respiration was unaffected. However, there were patterns in this study suggesting there may be implications of suspended sediments for juvenile $H$. iris, including direct impacts such as; slowed growth, decreased respiration rate, and decreased mucus production. These are all interlinked and may have negative consequences for $H$. iris. Negative consequences could include the blocking of the gills of $H$. iris preventing sufficient oxygen consumption and insufficient energy reserves. Consequently, exposure to elevated suspended sediment loads over long time periods may lead to physiological changes, and alter the growth and reproductive success of $H$. iris. Sediment may initiate a trade-off between energy allocation towards removal of sediments in the mantle cavity, rather than somatic growth and investment in reproduction (Helidoniotis et al. 2011). Reduction in energy towards reproduction could affect the quality and quantity of sperm and eggs produced and contribute to overall recruitment failure (Phillips \& Shima 2006).

The response of a species to increased disturbance from sediment can be complex and difficult to predict due to a combination of both direct and indirect effects. For H. iris, the lack of knowledge around both direct and indirect effects of suspended sediments 
may make them even more vulnerable. Indirect mechanisms include burial and smothering, changes in suitable substrate, decreased food (by limiting light availability for growth of algae) (Fabricius 2005). This could lead to H. iris could becoming less resistant to fishing pressure, and natural disturbances, eventually seeing population declines in $H$. iris over time.

\section{Implications to industry}

Growth of $H$. iris is asymptotic, with growth occurring within the first $30 \%$ of its lifespan (Rogers-Bennett et al. 2002). Trends in the data indicate that $H$. iris may be sensitive to increased sediment concentrations at this age. Worldwide, abalone fisheries are either in decline or face closure (Hobday et al. 2000; Gordon \& Cook 2013), which makes them prone to serial depletion, low recruitment and over-fishing. On top of fishing pressure, there are also other human impacts such as sedimentation. Sedimentation could cause slowed growth rates and can have implications for $H$. iris fisheries, causing variability in the resource quantity and quality. Possible economic implications for the fishery for $\mathrm{H}$. iris are that it may take longer to reach harvestable size and to gain returns.

\section{Limitations/Improvements}

One limitation of this study was that the level of suspended sediments used in the experiment may have been too low to elicit a response. For any future work, sediment concentrations based on those from regions in New Zealand with high sediment loads could be used, which may lead to more conclusive results for both growth and respiration.

In the mucus experiment, there was some uncertainly around whether mucus was produced but was not detected by weighing, and / or whether sediment was ingested by the animals retained within the mantle cavity of $H$. iris. This could have confounded the mucus production measurements. The duration that $H$. iris was subjected to suspended sediment was also short. Increasing the length of time for the mucus experiment could better improve our understanding of the long term effects sediment may have on $H$. iris populations. Future work could use a variety of size ranges of $H$. 
iris as the present study only concentrated on juvenile $H$. iris. Effects of suspended sediment have not yet been tested on spat or adults.

The present study indicates suspended sediment had no significant effect on the growth and oxygen consumption of $H$. iris, but more work is required, as mentioned above. There were trends in the data indicating that smaller sized $H$. iris were less resistant to the effects of suspended sediments. There was also a significant reduction in mucus production. Field experiments possibly involving translocating $H$. iris and estimating growth rates at a variety of locations subjected to a range of suspended sediment loads, could supplement laboratory experiments, and provide valuable information on in situ growth responses.

\section{Recommendations / Conclusions}

New Zealand's central and local government agencies as well as land-owners should be wary sedimentation rates. There is evidence to suggest there may be negative effects not only to $H$. iris, but also other marine organisms. The present study only looked at acute pulses of sediment over a short period of time. With increasing property development to accommodate to New Zealand's growing population, land clearance for forestry and conversion for farming, as a consequence the delivery of sediment into the marine environment will increase without careful planning and implementation of protective measures and controls. If sedimentation, rates were to increase there may have to be a re-evaluation of erosion control measures, and this should be done around rivers that are highly vulnerable to sediment, and eventually link to the marine environment. Identifying areas along waterways that have fragile soils and by changing earthwork strategies to those with a more low impact design will ultimately help mitigate the delivery of sediments into the marine environment. This will benefit marine animals and plants, particularly sedentary marine invertebrates like $H$. iris. Mitigation of sediments entering water-ways has been successful through measures as increasing riparian planting on banks (Parkyn et al. 2003). The Mangaotama project in Waikato demonstrated the effectiveness of protecting and restoring riparian land and wetlands by fencing and planting to reduce sediments into rivers, and eventually the marine environment (Smiley 2012). The economic benefits of industry (agriculture and industry in general) needs to be weighed up against the cost to the environment. Effective 
management will only be successful through the level of compliance by all parties involved in land-based activities that could potentially affect the marine environment (Salm \& Siirila 2000). These include; farming, property development, agriculture and forestry.

The present study has led to a better understanding of the potential implications of suspended sediment, not only for $H$. iris, but also for other abalone species. Although, it could be that sediment doesn't affect juvenile $H$. iris, sediment does have negative effects on at least one stage of the life-history (larval) of H. iris (Phillips and Shima 2006). New Zealand central and local government agencies need to be aware of these potential impacts on valuable fisheries such as $H$. iris, and ensure that the impacts of land-based activities are mitigated. 


\section{Acknowledgments}

First and foremost I would like to thank my primary supervisor Dr Sonja Miller, for her ongoing help, guidance and commitment to me throughout my thesis. I know I wouldn't have been able to complete this thesis without her. I would also like to thank my secondary supervisor Professor Joe Zuccarello for his guidance and advice. John van der Sman for experimental set-up. Financial support through Te Rōpu Āwhina and Tumau award. Graeme Moss for providing Haliotis iris for the experiments. Tepak Industries for providing containers for the experiments.

I would like to express thanks to my friends and co-workers at VUCEL for their input and guidance. Lastly I'd like to thank my family, my Mum and Dad, Sara-Anne, Patricia, Mike and Ivana for their love and support. Thank you for always being there! 


\section{Appendix}

\section{Appendix A}

Individual measurements and mean measurement of a standard New Zealand 20 cent piece. Actual size $=21.75 \mathrm{~mm}$.

\begin{tabular}{|l|l|l|}
\hline Replication & $\begin{array}{l}\text { Measurement (Ellis } \\
\text { et al. 2002) of 20c } \\
\text { piece coin }\end{array}$ & $\begin{array}{l}\text { Measurement (Ellis } \\
\text { et al. 2002) of small } \\
\text { H. iris shell }\end{array}$ \\
\hline $\mathbf{1}$ & 21.7 & 20.90 \\
\hline $\mathbf{2}$ & 21.7 & 20.86 \\
\hline $\mathbf{3}$ & 21.69 & 20.87 \\
\hline $\mathbf{4}$ & 21.7 & 20.89 \\
\hline $\mathbf{5}$ & 21.7 & 20.88 \\
\hline $\mathbf{6}$ & 21.69 & 20.89 \\
\hline $\mathbf{7}$ & 21.69 & 20.89 \\
\hline $\mathbf{8}$ & 21.68 & 20.90 \\
\hline $\mathbf{9}$ & 21.7 & 20.88 \\
\hline $\mathbf{1 0}$ & 21.7 & 20.87 \\
\hline Mean & 21.695 & 20.883 \\
\hline $\begin{array}{l}\text { Standard } \\
\text { deviation }\end{array}$ & 0.0071 & 0.013375 \\
\hline Standard error & 0.0015 & 0.002927 \\
\hline $\begin{array}{l}\mathbf{P} \text { (precision }= \\
\text { se/sample mean) }\end{array}$ & 0.0006 & 0.0002 \\
\hline $\begin{array}{l}\text { CV (coefficient } \\
\text { of variation) }\end{array}$ & 0.0003 & 0.0006 \\
\hline
\end{tabular}




\section{References}

Aguirre J.D. \& McNaught D.C. (2012). Ontogenetic variability in the habitat associations of Haliotis iris in central New Zealand. Marine and freshwater research, 63, 751-761.

Airoldi L. (1998). Roles of disturbance, sediment stress, and substratum retention on spatial dominance in algal turf. Ecology, 79, 2759-2770.

Au D., Pollino C., Wu R., Shin P., Lau S. \& Tang J. (2004). Chronic effects of suspended solids on gill structure, osmoregulation, growth, and triiodothyronine in juvenile green grouper Epinephelus coioides. Marine Ecology Progress Series, 266, 255-264.

Babcock R. \& Davies P. (1991). Effects of sedimentation on settlement of Acropora millepora. Coral Reefs, 9, 205-208.

Bak R. \& Elgershuizen J. (1976). Patterns of oil-sediment rejection in corals. Marine Biology, 37, 105-113.

Barkai R. \& Griffiths C. (1988). An energy budget for the South African abalone Haliotis midae Linnaeus. Journal of molluscan studies, 54, 43-51.

Bash J., Berman C.H. \& Bolton S. (2001). Effects of turbidity and suspended solids on salmonids. In. University of Washington Water Center.

Blaschke P., Anstey C. \& Forsyth F. (2009). Ecological restoration priorities for the Porirua stream and its catchment. Blaschke and Rutherford Environmental Consultants. Wellington.

Bricelj V., Malouf R. \& De Quillfeldt C. (1984). Growth of juvenile Mercenaria mercenaria and the effect of resuspended bottom sediments. Marine biology, 84, 167-173.

Burkett V. (2013). Coastal Impacts, Adaptation, and Vulnerabilities: A Technical Input to the 2013 National Climate Assessment. Island Press.

Carter L. (1975). Sedimentation on the continental terrace around New Zealand: a review. Marine geology, 19, 209-237.

Cheung S., Chan H., Liu C. \& Shin P. (2008). Effect of prolonged hypoxia on food consumption, respiration, growth and reproduction in marine scavenging gastropod Nassarius festivus. Marine pollution bulletin, 57, 280-286.

Cheung S. \& Shin P. (2005). Size effects of suspended particles on gill damage in green-lipped mussel Perna viridis. Marine pollution bulletin, 51, 801-810.

Chew C.A., Hepburn C.D. \& Stephenson W. (2013). Low-level sedimentation modifies behaviour in juvenile Haliotis iris and may affect their vulnerability to predation. Marine biology, 1-9.

Chin A. (2006). Urban transformation of river landscapes in a global context. Geomorphology, 79, 460-487.

Clarke C.B. (2001). Growth and survival of Haliotis iris in northern New Zealand, with special reference to aquaculture.

Cook P.A. \& Roy Gordon H. (2010). World abalone supply, markets, and pricing. Journal of Shellfish Research, 29, 569-571. 
Creese R. \& Underwood A. (1982). Analysis of inter-and intra-specific competition amongst intertidal limpets with different methods of feeding. Oecologia, 53, 337-346.

Crofts D.R. (1937). The development of Haliotis tuberculata, with special reference to organogenesis during torsion. Philosophical Transactions of the Royal Society of London. Series B, Biological Sciences, 228, 219-268.

Crowe T., Thompson R., Bray S. \& Hawkins S. (2000). Impacts of anthropogenic stress on rocky intertidal communities. Journal of Aquatic Ecosystem Stress and Recovery (Formerly Journal of Aquatic Ecosystem Health), 7, 273-297.

Davies M.S. \& Hawkins J. (1998). Mucus from marine molluscs. Advances in Marine Biology, 34, 1-71.

Dawe I. (2007). Sea-Level Rise - A New Zealand Context. In. Wellington Regional Council Wellington

Day R., Hawkes G. \& Gomelyuk V. (2001). In situ time-stamping of abalone shells to determine how abalone stocks can be aged. Fisheries Research and Development Corporation (FRDC) Report, Project, 1-49.

Dehnel P.A. (1955). Rates of growth of gastropods as a function of latitude. Physiological Zoology, 28, 115-144.

Denny M.W. (1984). Mechanical properties of pedal mucus and their consequences for gastropod structure and performance. American Zoologist, 24, 23-36.

Devlin M. \& Brodie J. (2005). Terrestrial discharge into the Great Barrier Reef Lagoon: nutrient behavior in coastal waters. Marine Pollution Bulletin, 51, 9-22.

Di Leva R. (2013). Recommended citation: Forest \& Bird (2013). Aquaculture Best Fish Guide 2013-2014. Royal Forest and Bird Protection Society of New Zealand Inc, Wellington.

Donovan D.A. \& Carefoot T.H. (1998). Effect of activity on energy allocation in the northern abalone, Haliotis kamtschatkana (Jonas). Journal of Shellfish Research, 17, 729-736.

Eggert H. \& Kahui V. (2013). Reference-dependent behaviour of paua (abalone) divers in New Zealand. Applied Economics, 45, 1571-1582.

Ellis J., Cummings V., Hewitt J., Thrush S. \& Norkko A. (2002). Determining effects of suspended sediment on condition of a suspension feeding bivalve Atrina zelandica : results of a survey, a laboratory experiment and a field transplant experiment. Journal of experimental marine biology and ecology, 267, 147-174.

Fabricius K.E. (2005). Effects of terrestrial runoff on the ecology of corals and coral reefs: review and synthesis. Marine pollution bulletin, 50, 125-146.

Fleming A., Hone P. \& Higham J. (1997). The effect of water velocity on consumption and growth of greenlip abalone in tanks. In: Presentation at the fourth annual abalone aquaculture workshop. Port Fairy, Australia.

Fletcher C. (1992). Stress and water balance in the plaice Pleuronectes platessa. Journal of Comparative Physiology B, 162, 513-519.

Foster B. (1971). Desiccation as a factor in the intertidal zonation of barnacles. Marine biology, 8, 12-29.

Fry F. (1971). 1 The Effect of Environmental Factors on the Physiology of Fish. Fish physiology, 6, 1-98.

Gordon H.R. \& Cook P.A. (2004). World abalone fisheries and aquaculture update: supply and market dynamics. Journal of shellfish Research, 23, 935-940. 
Gordon H.R. \& Cook P.A. (2013). World Abalone Supply, Markets, and Pricing: 2011 Update. Journal of Shellfish Research, 32, 5-7.

Gosselin L.A. \& Qian P.-Y. (1997). Juvenile mortality in benthic marine invertebrates. Marine Ecology Progress Series, 146, 265-282.

Gray J.S. (1997). Marine biodiversity: patterns, threats and conservation needs. Biodiversity \& Conservation, 6, 153-175.

Griffiths G. \& Glasby G. (1985). Input of river-derived sediment to the New Zealand continental shelf: I. Mass. Estuarine, coastal and shelf science, 21, 773-787.

Halpern B.S., Walbridge S., Selkoe K.A., Kappel C.V., Micheli F., D'Agrosa C., Bruno J.F., Casey K.S., Ebert C. \& Fox H.E. (2008). A global map of human impact on marine ecosystems. Science, 319, 948-952.

Harris J.O., B Maguire G., Edwards S.J. \& Johns D.R. (1999). Low dissolved oxygen reduces growth rate and oxygen consumption rate of juvenile greenlip abalone, Haliotis laevigata Donovan. Aquaculture, 174, 265-278.

Harris J.O., Maguire G.B., Edwards S. \& Hindrum S.M. (1998). Effect of ammonia on the growth rate and oxygen consumption of juvenile greenlip abalone, Haliotis laevigata. Aquaculture, 160, 259-272.

Hauraki Maori Trust Board (1999). Maori Indicators Case Study. Wellington, Ministry for the Environment, Hauraki Maori Trust Board. In: (ed. Report HCI). Environmental Performance Indicators Programme of the Ministry for the Environment.

Helidoniotis F., Haddon M., Tuck G. \& Tarbath D. (2011). The relative suitability of the von Bertalanffy, Gompertz and inverse logistic models for describing growth in blacklip abalone populations (Haliotis rubra) in Tasmania, Australia. Fisheries Research, 112, 13-21.

Henley W., Patterson M., Neves R. \& Lemly A.D. (2000). Effects of sedimentation and turbidity on lotic food webs: a concise review for natural resource managers. Reviews in Fisheries Science, 8, 125-139.

Hobday A.J., Tegner M.J. \& Haaker P.L. (2000). Over-exploitation of a broadcast spawning marine invertebrate: decline of the white abalone. Reviews in Fish Biology and Fisheries, 10, 493-514.

Hodgson G. (1990). Sediment and the settlement of larvae of the reef coral Pocillopora damicornis. Coral Reefs, 9, 41-43.

Hooker N. \& Morse D.E. (1985). Abalone: the emerging development of commercial cultivation in the United States. Crustacean and mollusc aquaculture in the United States. Wesport, Connecticut: AVI Publishing Company, 365-413.

Hooker S., Creese R. \& Jeffs A. (1997). Growth and demography of paua Haliotis iris (Mollusca: Gastropoda) in northeastern New Zealand. Molluscan Research, 18, 299-311.

Hooper C., Day R., Slocombe R., Benkendorff K. \& Handlinger J. (2011). Effect of movement stress on immune function in farmed Australian abalone (hybrid Haliotis laevigata and Haliotis rubra). Aquaculture, 315, 348-354.

Hubbard J.A. \& Pocock Y.P. (1972). Sediment rejection by recent scleractinian corals: a key to palaeo-environmental reconstruction. Geologische Rundschau, 61, 598626.

Hughes T.P., Bellwood D.R., Folke C., Steneck R.S. \& Wilson J. (2005). New paradigms for supporting the resilience of marine ecosystems. Trends in ecology \& evolution, 20, 380-386. 
Hume, M.O.Green \& S.Elliot (2010). Tauranga Harbour Sediment Study: Assesment of Prediction for Management In. NIWA Silverdale Road, Hamilton

Kemp P., Sear D., Collins A., Naden P. \& Jones I. (2011). The impacts of fine sediment on riverine fish. Hydrological Processes, 25, 1800-1821.

Kennelly S.J. (1987). Inhibition of kelp recruitment by turfing algae and consequences for an Australian kelp community. Journal of Experimental Marine Biology and Ecology, 112, 49-60.

Kiørboe T., Møhlenberg F. \& Nøhr O. (1981). Effect of suspended bottom material on growth and energetics in Mytilus edulis. Marine Biology, 61, 283-288.

Koike Y., Flassch J. \& Mazurier J. (1979). Biological and ecological studies on the propagation of the ormer, Haliotis tuberculata Linnaeus. II. Influence of food and density on the growth of juveniles. La mer, 17, 43-52.

Lebel J.M., Giard W., Favrel P. \& Boucaud-Camou E. (1996). Effects of different vertebrate growth factors on primary cultures of hemocytes from the gastropod mollusc, Haliotis tuberculata. Biology of the Cell, 86, 67-72.

Leitman A. (1992). The effects of gas supersaturation on the behaviour, growth and mortality of red abalone, Haliotis rufescens (Swainson). SA Shepherd, MJ Tegner \& SA Guzma $n$ del Pro o, editors. Abalone of the world: biology, fisheries and culture. Oxford: Fishing News Books, 75-85.

Lohrer A.M., Hewitt J.E. \& Thrush S.F. (2006). Assessing far-field effects of terrigenous sediment loading in the coastal marine environment. Marine Ecology Progress Series, 315, 13.

Maltby L. (1999). Studying stress: the importance of organism-level responses. Ecological Applications, 9, 431-440.

McBride S.C., Rotem E., Ben-Ezra D. \& Shpigel M. (2001). Seasonal energetics of Haliotis fulgens (Philippi) and Haliotis tuberculata (L.). Journal of Shellfish Research, 20, 659-666.

McKee B., Aller R., Allison M., Bianchi T. \& Kineke G. (2004). Transport and transformation of dissolved and particulate materials on continental margins influenced by major rivers: benthic boundary layer and seabed processes. Continental Shelf Research, 24, 899-926.

McShane P.E. (1995). Estimating the abundance of abalone: the importance of patch size. Marine and freshwater research, 46, 657-662.

McShane P.E. \& Naylor J.R. (1995). Depth can affect post-settlement survival of Haliotis iris (Mollusca: Gastropoda). Journal of experimental marine biology and ecology, 187, 1-12.

Miller D.C., Muir C.L. \& Hauser O.A. (2002). Detrimental effects of sedimentation on marine benthos: what can be learned from natural processes and rates? Ecological Engineering, 19, 211-232.

Minchin D. (1975). The righting response in Haliotids. The Veliger, 17.

Miner C., Altstatt J.M., Raimondi P.T. \& Minchinton T.E. (2006). Recruitment failure and shifts in community structure following mass mortality limit recovery prospects of black abalone. Marine Ecology Press Series, 327, 107.

Moran A.L. (1999). Size and performance of juvenile marine invertebrates: potential contrasts between intertidal and subtidal benthic habitats. American zoologist, 39, 304-312. 
Morrison M.A., Lowe M., Parsons D., Usmar N. \& McLeod I. (2009). A review of landbased effects on coastal fisheries and supporting biodiversity in New Zealand. Ministry of Fisheries.

Moss G.A., Illingworth J. \& Tong L.J. (1995). Comparing two simple methods to induce spawning in the New Zealand abalone (paua), Haliotis iris.

Naranjo S., Carballo J. \& García-Gómez J. (1996). Effects of environmental stress on ascidian populations in Algeciras Bay(southern Spain). Possible marine bioindicators? Marine Ecology Progress Series, 144, 119-131.

Naylor J., Andrew N. \& Kim S. (2006). Demographic variation in the New Zealand abalone Haliotis iris. Marine and freshwater research, 57, 215-224.

Newcombe C.P. \& Jensen J.O.T. (1996). Channel suspended sediment and fisheries: a synthesis for quantitative assessment of risk and impact. North American Journal of Fisheries Management, 16, 693-727.

Newcombe C.P. \& MacDonald D.D. (1991). Effects of suspended sediments on aquatic ecosystems. North American Journal of Fisheries Management, 11, 72-82.

Nixon S.W. (1995). Coastal marine eutrophication: a definition, social causes, and future concerns. Ophelia, 41, 199-219.

Onitsuka T., Kawamura T., Ohashi S., Iwanaga S., Horii T. \& Watanabe Y. (2008). Effects of sediments on larval settlement of abalone Haliotis diversicolor. Journal of experimental marine biology and ecology, 365, 53-58.

Onitsuka T., Kawamura T., Ohashi S., Iwanaga S., Horii T. \& Watanabe Y. (2010). Effects of delayed metamorphosis and delayed post-settlement feeding on postlarval survival and growth of the abalone Haliotis diversicolor. Aquaculture, 298, 239-244.

Parkyn S.M., Davies Colley R.J., Halliday N.J., Costley K.J. \& Croker G.F. (2003). Planted riparian buffer zones in New Zealand: do they live up to expectations? Restoration ecology, 11, 436-447.

Peck L., Culley M. \& Helm M. (1987). A laboratory energy budget for the ormer Haliotis tuberculata. Journal of experimental marine biology and ecology, 106, 103-123.

Peters E.C. \& Pilson M.E. (1985). A comparative study of the effects of sedimentation on symbiotic and asymbiotic colonies of the coral Astrangia danae Milne Edwards and Haime 1849. Journal of Experimental Marine Biology and Ecology, 92, 215-230.

Phillips D.J. (1977). The use of biological indicator organisms to monitor trace metal pollution in marine and estuarine environments a review. Environmental Pollution (1970), 13, 281-317.

Phillips N.E. \& Shima J.S. (2006). Differential effects of suspended sediments on larval survival and settlement of New Zealand urchins Evechinus chloroticus and abalone Haliotis iris. Marine Ecology Progress Series, 314, 149-158.

Poore G.C. (1972). Ecology of New Zealand abalones, Haliotis species (Mollusca: Gastropoda) New Zealand journal of marine and freshwater research, 6, 534559.

Preece M.A. \& Mladenov P.V. (1999). Growth and mortality of the New Zealand abalone Haliotis iris Martyn 1784 cultured in offshore structures and fed artificial diets. Aquaculture Research, 30, 865-877. 
Prince J., Sellers T., Ford W. \& Talbot S. (1988). Recruitment, growth, mortality and population structure in a southern Australian population of Haliotis rubra (Mollusca: Gastropoda). Marine biology, 100, 75-82.

Raffaelli D., Emmerson M., Solan M., Biles C. \& Paterson D. (2003). Biodiversity and ecosystem processes in shallow coastal waters: an experimental approach. Journal of Sea Research, 49, 133-141.

Ragg N.L. \& Taylor H.H. (2006). Heterogeneous perfusion of the paired gills of the abalone Haliotis iris Martyn 1784: an unusual mechanism for respiratory control. Journal of experimental biology, 209, 475-483.

Ragg N.L.C. (2003). Respiratory circulation in the abalone Haliotis iris.

Roberts R.D. \& Lapworth C. (2001). Effect of delayed metamorphosis on larval competence, and post-larval survival and growth, in the abalone Haliotis iris Gmelin. Journal of experimental marine biology and ecology, 258, 1-13.

Robinson N., Smith B., Cooke I. \& Strugnell J. (2012). A snail's pace: A preliminary analysis of the effects of stress and genetics on movement of Haliotis. Aquaculture.

Rogers-Bennett L., Haaker P.L., Huff T.O. \& Dayton P.K. (2002). Estimating baseline abundances of abalone in California for restoration. Reports of California Cooperative Oceanic Fisheries Investigations, 43, 97-111.

Rogers C.S. (1990). Responses of coral reefs and reef organisms to sedimentation. Marine ecology progress series. Oldendorf, 62, 185-202.

Ryan P.A. (1991). Environmental effects of sediment on New Zealand streams: a review. New Zealand journal of marine and freshwater research, 25, 207-221.

Sainsbury K. (1982). Population dynamics and fishery management of the paua, Haliotis iris I. Population structure, growth, reproduction, and mortality. New Zealand journal of marine and freshwater research, 16, 147-161.

Salm R.V. \& Siirila E. (2000). Marine and coastal protected areas: a guide for planners and managers. IUCN.

Scheid P. (1982). model for comparing gas-exchange systems in vertebrates. In: Companion to Animal physiology: papers from the 5th International Conference on Comparative Physiology held at Sandbjerg, Denmark, July 22-26, 1980/editors, CR Taylor, K. Johansen, L. Bolis. Cambridge [Cambridgeshire]: Cambridge University Press, 1982.

Scrosati R.A., Knox A.S., Valdivia N. \& Molis M. (2011). Species richness and diversity across rocky intertidal elevation gradients in Helgoland: testing predictions from an environmental stress model. Helgoland Marine Research, $65,91-102$.

Searle T., Roberts R.D. \& Lokman P.M. (2006). Effects of temperature on growth of juvenile blackfoot abalone, Haliotis iris Aquaculture Research, 37, 1441-1449.

Seki T. \& Kan-No H. (1981). Induced settlement of the Japanese abalone, Haliotis discus hannai, veliger by the mucous trails of the juvenile and adult abalones. Bulletin of Tohoku Regional Fisheries Research Laboratory.

Shepherd S. \& Hearn W. (1983). Studies on Southern Australian abalone (genus Haliotis). IV. Growth of $H$. laevigata and $H$. ruber. Marine and freshwater research, 34, 461-475.

Shepherd S., Lowe D. \& Partington D. (1992). Studies on southern Australian abalone (genus Haliotis) XIII: larval dispersal and recruitment. Journal of experimental marine biology and ecology, 164, 247-260. 
Shin P., Yau F., Chow S., Tai K. \& Cheung S. (2002). Responses of the green-lipped mussel Perna viridis to suspended solids. Marine pollution bulletin, 45, 157162.

Short F.T. \& Wyllie-Echeverria S. (1996). Natural and human-induced disturbance of seagrasses. Environmental conservation, 23, 17-27.

Simkiss K. \& Wilbur K. (1977). The molluscan epidermis and its secretions. Comparative Biology of Skin. Academic, London, 35-76.

Smiley D. (2012). The effect of an integrated catchment management plan on the greenhouse gas balance of the Mangaotama catchment of the Whatawhata Hill Country Research Station: a thesis presented in partial fulfillment of the requirements for the degree of Master of Science in Ecology at Massey University, Manawatu, New Zealand. In.

Smith A.M. (1991). The role of suction in the adhesion of limpets. Journal of experimental biology, 161, 151-169.

Sokal R. \& Rohlf F. (1981). Biometry, 1981. WH Freemany, San Francisco.

Steckbauer A., Duarte C.M., Carstensen J., Vaquer-Sunyer R. \& Conley D. (2011). Ecosystem impacts of hypoxia: thresholds of hypoxia and pathways to recovery. Environmental Research Letters, 6, 025003.

Steger K.K. \& Gardner J. (2007). Laboratory experiments on the effects of variable suspended sediment concentrations on the ecophysiology of the porcelain crab Petrolisthes elongatus (Milne Edwards, 1837). Journal of experimental marine biology and ecology, 344, 181-192.

Stevens P.M. (1987). Response of excised gill tissue from the New Zealand scallop Pecten novaezelandiae to suspended silt. New Zealand journal of marine and freshwater research, 21, 605-614.

Taylor H. \& Ragg N. (2005). The role of body surfaces and ventilation in gas exchange of the abalone, Haliotis iris. Journal of Comparative Physiology B, 175, 463478.

Todd M.-E. \& Dehnel P.A. (1960). Effect of temperature and salinity on heat tolerance in two grapsoid crabs, Hemigrapsus nudus and Hemigrapsus oregonensis. The Biological Bulletin, 118, 150-172.

Todd P.A., Ong X. \& Chou L.M. (2010). Impacts of pollution on marine life in Southeast Asia. Biodiversity and Conservation, 19, 1063-1082.

Tong L., Moss G., Shepherd S., Tegner M. \& Próo S.d. (1992). The New Zealand culture system for abalone. In: Abalone of the world: biology, fisheries and culture. Proceedings of the 1st International Symposium on Abalone. Fishing News Books Ltd, pp. 583-591.

Townsend M. \& Thrush S. (2010). Ecosystem functioning, goods and services in the coastal environment. In: Auckland Regional Council Technical report (ed. Stewart M). Auckland Regional Council Silverdale Road, Hamilton.

Tung C.H. \& Alfaro A.C. (2011). Effect of dietary protein and temperature on the growth and health of juvenile New Zealand black footed abalone (Haliotis iris). Aquaculture Research, 42, 366-385.

Tyler D.T. (2012). Growth and energetic status of the New Zealand black-footed paua (Haliotis iris). In. ResearchSpace@ Auckland.

Umar M., McCook L. \& Price I. (1998). Effects of sediment deposition on the seaweed Sargassum on a fringing coral reef. Coral Reefs, 17, 169-177. 
Vermeij G.J. \& Signor P.W. (1992). The geographic, taxonomic and temporal distribution of determinate growth in marine gastropods. Biological Journal of the Linnean Society, 47, 233-247.

Viera M., Gómez Pinchetti J., Courtois de Vicose G., Bilbao A., Suárez S., Haroun R. \& Izquierdo M. (2005). Suitability of three red macroalgae as a feed for the abalone Haliotis tuberculata coccinea Aquaculture, 248, 75-82.

Vilchis L.I., Tegner M.J., Moore J.D., Friedman C.S., Riser K.L., Robbins T.T. \& Dayton P.K. (2005). Ocean warming effects on growth, reproduction, and survivorship of southern California abalone. Ecological Applications, 15, 469480.

Wang G.-j., Xie J., Yu D.-g., Wu L. \& Hu Z.-y. (2007). Physiological responses of abalone Haliotis divericolor to suspended sediment stress Journal of Dalian Fisheries University, 5, 008.

Wardle P. (1991). Vegetation of New Zealand. CUP Archive.

Wells R.M.G., McShane P.E., Ling N., Wong R.J., Lee T.O.C. \& Baldwin J. (1998). Effect of Wave Action on Muscle Composition, Metabolites and Growth Indices in the New Zealand Abalone, Paua (Haliotis iris), with Implications for Harvesting and Aquaculture. Comparative Biochemistry and Physiology Part B: Biochemistry and Molecular Biology, 119, 129-136.

Wickins J. (1981). Water quality requirements for intensive aquaculture: a review. Schriften der Bundesforschungsanstalt fuer Fischerei, 16.

Wilber D.H. \& Clarke D.G. (2001). Biological effects of suspended sediments: a review of suspended sediment impacts on fish and shellfish with relation to dredging activities in estuaries. North American Journal of Fisheries Management, 21, 855-875.

Will M., Hale M.L., Schiel D.R. \& Gemmell N.J. (2011). Low to moderate levels of genetic differentiation detected across the distribution of the New Zealand abalone, Haliotis iris. Marine Biology, 158, 1417-1429.

Windom H. \& Stickney R.R. (1976). Environmental aspects of dredging in the coastal zone. Critical Reviews in Environmental Science and Technology, 6, 91-109.

Wright I. (2012). Water Quality In New Zealand- Understanding the Science In. 